\title{
Relationship of Worldwide Rocket Launch Crashes with Geophysical Parameters
}

\author{
N. Romanova, ${ }^{1}$ N. Crosby, ${ }^{2}$ and V. Pilipenko ${ }^{3}$ \\ ${ }^{1}$ Institute of Physics of the Earth, Russian Academy of Sciences, Gruzinskaya Street 10-1, Moscow 123995, Russia \\ ${ }^{2}$ Belgian Institute for Space Aeronomy, Ringlaan 3 Avenue Circulaire, Brussels 1180, Belgium \\ ${ }^{3}$ Space Research Institute (IKI), Russian Academy of Sciences, Profsoyuznaya Street 84/32, Moscow 117997, Russia \\ Correspondence should be addressed to N. Romanova; runatka@mail.ru
}

Received 7 November 2012; Revised 14 February 2013; Accepted 8 April 2013

Academic Editor: Umberta Tinivella

Copyright (C) 2013 N. Romanova et al. This is an open access article distributed under the Creative Commons Attribution License, which permits unrestricted use, distribution, and reproduction in any medium, provided the original work is properly cited.

\begin{abstract}
A statistical comparison of launch crashes at different worldwide space ports with geophysical factors has been performed. A comprehensive database has been compiled, which includes 50 years of information from the beginning of the space age in 1957 about launch crashes occurring world-wide. Special attention has been paid to statistics concerning launches at the largest space ports: Plesetsk, Baikonur, Cape Canaveral, and Vandenberg. In search of a possible influence of geophysical factors on launch failures, such parameters as the vehicle type, local time, season, sunspot number, high-energy electron fluxes, and solar proton events have been examined. Also, we have analyzed correlations with the geomagnetic indices as indirect indicators of the space weather condition. Regularities found in this study suggest that further detailed studies of space weather effects on launcher systems, especially in the high-latitude regions, should be performed.
\end{abstract}

\section{Introduction}

Since the beginning of the space era in 1957 more than 5000 space vehicles have been launched from different space ports in the world. Details of world-wide space ports (latitude/longitude, operational period, total number of launches, and launch crashes) are listed in Table 1, and their locations are shown in Figure 1. However, 384 of these launches were reported to have failed through 2008. The total number of launches and crashes at the major space ports from 1957 till 2008 is shown in Figure 2.

Launch crashes are commonly attributed to engineering faults in the rocket equipment and/or control system during launch. Specifically, the reason behind launch crashes can be due to a wide range of reasons: construction errors of the rocket launcher and launch complex systems; breakdown in the preparation process; human factor. Crashes during the prime stage phase of launch (up to an altitude of $\sim 100 \mathrm{~km}$ ) are mainly caused by combustion instability, ignition failure, turbopump overheating, insufficient control gain, staging electrical disconnect, and so forth. Any such failure results in enormous financial losses for the space industry and insurance companies [1]. A possible influence of geophysical factors (meteorological or space environment) on rocket systems may be questioned. Even though the number of critical situations during takeoff and space flight related to the space weather is probably not very high as compared with general statistics, even a single event causes a huge financial loss.

There is ever growing evidence that the dynamic space environment may have hazardous effect on high-technology systems in general, and on electronic equipment of nearEarth orbiting satellites in particular [2,3]. Clouds of low-energy electrons may produce differential charging of spacecraft surfaces and cause electrical discharges in control systems, whereas penetrating radiation and high-energy electrons can produce volume charging and destructive electrical discharges [4-7]. The effects of space weather on ground technology infrastructure [8] and aviation [9] are actively examined. According to an estimate of the US Aircraft Insurance Group, the space weather impact was responsible for $\sim \$$ 0,5 billion revenue loss in 1996-2000 [10, 11]. However, the possible impact of space weather on rocket launches has not 
TABLE 1: Main world space ports.

\begin{tabular}{|c|c|c|c|c|c|c|}
\hline Space port & State owned & Lat. $^{\circ}$ & Long..$^{\circ}$ & Period of operation & \# of launches & \# of crashes \\
\hline (1) Plesetsk & USSR/Russia & $63 \mathrm{~N}$ & $41 \mathrm{E}$ & 1966-present & 1558 & 66 \\
\hline (2) Baikonur & USSR/Russia & $46 \mathrm{~N}$ & $62 \mathrm{E}$ & 1957-present & 1288 & 109 \\
\hline (3) Cape Canaveral & USA & $28 \mathrm{~N}$ & $80 \mathrm{~W}$ & 1957-present & 638 & 62 \\
\hline (4) Vandenberg AFB & USA & $34 \mathrm{~N}$ & $120 \mathrm{~W}$ & 1959-present & 586 & 50 \\
\hline (5) Centre Spatial Guyanais, Kourou & Guyane Francaise & $05 \mathrm{~N}$ & $52 \mathrm{~W}$ & 1968-present & 189 & 14 \\
\hline (6) Kapustin Jar & USSR/Russia & $48 \mathrm{~N}$ & $45 \mathrm{E}$ & 1961-1999 & 100 & 16 \\
\hline (7) Xichang Space Center & China & $28 \mathrm{~N}$ & $102 \mathrm{E}$ & 1984-present & 47 & 4 \\
\hline (8) Tanegashima & Japan & $30 \mathrm{~N}$ & $130 \mathrm{E}$ & 1975-present & 44 & 2 \\
\hline (9) Naval Missile Facility, Point Arguello & USA & $34 \mathrm{~N}$ & $120 \mathrm{~W}$ & 1986-present & 44 & 12 \\
\hline (10) Wallops Flight Facility & USA & $38 \mathrm{~N}$ & $75 \mathrm{~W}$ & 1960-present & 42 & 3 \\
\hline (11) Jiuquan & China & $40 \mathrm{~N}$ & $100 \mathrm{E}$ & 1970-present & 42 & 5 \\
\hline (12) Kagoshima & Japan & $31 \mathrm{~N}$ & $130 \mathrm{E}$ & 1966-2006 & 35 & 8 \\
\hline (13) Taiyuan & China & $37 \mathrm{~N}$ & $112 \mathrm{E}$ & 1988-2006 & 23 & 2 \\
\hline (14) Sea Launch, Platform Odyssey & USA, Russia, Ukraine, Norway & 0 & $154 \mathrm{~W}$ & 1999-present & 24 & 2 \\
\hline Others & & - & - & 1957-present & 229 & 29 \\
\hline
\end{tabular}

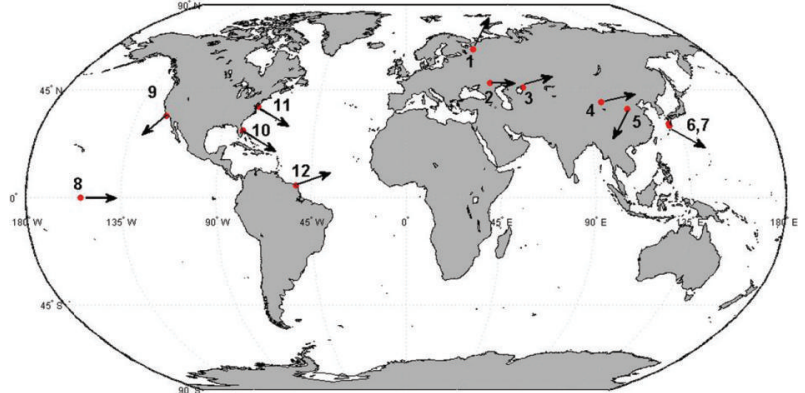

FIGURE 1: World map locations of main space sites. Arrows indicate the main direction of rocket trajectory after launch. The key worldwide spaceports are as follows: (1) Plesetsk, (2) Kapustin Yar, (3) Baykonur, (4) Jiuquan Space Center, (5) Taiyuan Satellite Launch Center, (6) Tanegashima Space Center, (7) Kagoshima Space Center, (8) Sea Launch, (9) Vandenberg, (10) Cape Canaveral, (11) Wallops space factory, and (12) Centre Spatial Guyanais (Kourou).

been thoroughly examined yet. So, it is still uncertain whether the rocket community should introduce some procedures for mitigating the space weather adverse influence on rocket launches.

Cases of space vehicle failures during magnetic storms have been noticed by Romanova et al. [12], who analyzed the statistics of launchers at the Plesetsk site for the period 19662005. They found that the relative number of launch crashes was nearly 2 times higher at summertime than during other seasons and statistically increased during elevated geomagnetic activity. The reason of this effect and its statistical validation needs further studies.

In this paper, we examine statistically all world-wide launch crashes occurring at all major space sites from 1957 to 2008. Though the number of available space weather and geophysical parameters is very limited, we believe that examination of even basic indirect parameters could be worthwhile to outline directions of further more detailed studies. If crashes do not depend on geophysical/space environment, then the corresponding geophysical parameters during failure events should have random distributions. The randomness of pertinent geophysical parameters will be evaluated in this study. The data used are described in Section 2. Section 3 presents general statistical properties of the launch fail-ures, including their seasonal and diurnal variations, and dependence on vehicle type. In Section 4, the dependence of failures on solar and geomagnetic activity at various launching sites is analyzed, and, in Section 5, the results of the study are discussed and main conclusions are given.

\section{Spacecraft Launch Databases}

For this study, we have compiled a complete spacecraft launch database based on information available from the following resources:

(1) History of Spaceflight website by J. McDowell (http:// www.planet4589.org/space/);

(2) Encyclopedia "Cosmonautics" (Chronicle of accidents and catastrophes) by A. Zheleznyakov (http:// www.cosmoworld.ru/);

(3) Vehicle Launch Log from Encyclopedia Astronautica (http://www.astronautix.com/data/);

(4) Southwest's Source for Space and Astronomy Information (http://www.spacearchive.info/);

(5) SPACEWARN monthly Bulletin of the NASA National Space Science Data Center (http://nssdc.gsfc.nasa .gov/spacewarn/).

This merged database contains information about successful launches as well as failures and is available for the scientific community via the Internet (http://geomagnet.ifz.ru/). The database contains information about launch times, launching sites or platforms, vehicle types, and successfulness of launches. For failed launches we tried to find a more 


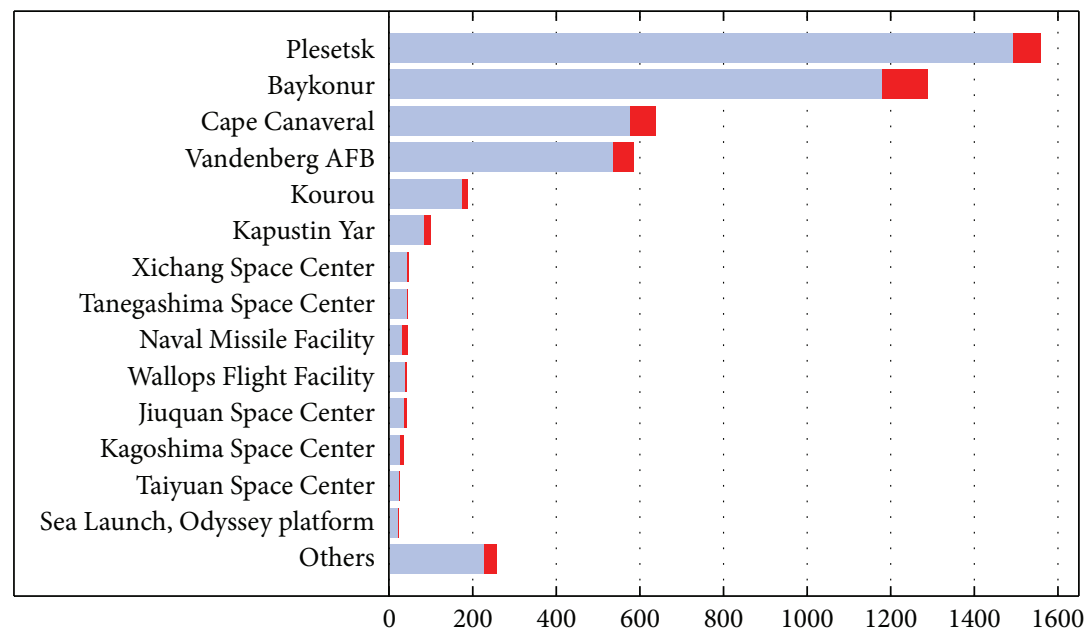

FIGURE 2: Number of launches from the most-used space ports in the world from 1957 till 2008. Red mark denotes crashes.

detailed description of the problem from other additional resources (news, space agency official bulletins, etc.). In our analysis, an event has been classified as "launch crash" if the reason by which the spacecraft did not reach its planned orbit cannot be explained neither by rocket destruction nor the malfunction of the launcher's control system. The compiled database comprises the 50-year period, from 1957 to 2008. The statistical analysis of failed events has been made for the major sites: Cape Canaveral, Plesetsk, Baykonur, and Vandenberg. For other launch sites the statistics is not large enough for statistically significant results. Emergencies at the launch pad before the actual takeoff (e.g., explosion during prelaunch preparation, fuel fire, loss of launcher engine thrust, etc.) have been excluded from the analysis. The launches of all manned missions (e.g., NASA Shuttle from Canaveral) are not included, because of limited statistics and specifics of the prelaunch operation. Thus, only the failures which occurred in the high-altitude atmosphere or ionosphere during the takeoff or initial phase of the mission are included. The major part of the failures occurred at altitudes ranging from 15 to $100 \mathrm{~km}$; however, it is not possible to give a more precise distribution of failure rate along the altitude because of lack of information.

The long-term databases of direct measurements of radiation in space (e.g., fluxes of precipitated high-energy particles) at low altitudes are not available, therefore, for statistical analysis we use, as indirect measures of the space weather, various solar and geomagnetic indices: sunspot number (Wolf's number) $R$; planetary geomagnetic index $K_{p}$ characterizing the midlatitude geomagnetic activity; $A E$ index measuring the intensity of auroral disturbances; $D_{\text {st }}$ index characterizing the ring current intensity. Additionally, we use the solar proton flux intensity $J$ with energies $E>$ $1,2,4$, and $10 \mathrm{MeV}$ measured by interplanetary monitors IMP5-8; the high-energy electron fluxes $(E=50 \mathrm{keV}-2 \mathrm{MeV})$ from geostationary satellites LANL and GOES.

The parameters $R, K_{p}$, and $J$ have been taken from the OMNI database (http://omniweb.gsfc.nasa.gov/); geomagnetic indices $D_{\text {st }}$ and $A E$ have been provided by the World
Data Center for Geomagnetism (http://wdc.kugi.kyoto-u.ac .jp/aedir/index.html). Additionally, the index $P$ characterizing the total power input by auroral particles precipitating into the Northern polar region, measured by NOAA satellites (http://www.swpc.noaa.gov/pmap/), has been used.

\section{General Properties of Crash Probability and Analysis Methods}

Yearly distributions of the number of launches, crash launches, and relative number of crashes for all world-wide launching sites from 1957 till 2007 are shown in Figure 3. These plots show that the number of failures was very high at the beginning of the space era (1957-1961), then slowly decreased till 1975 and since then has remained nearly at the same level. As a measure of failure rate we use the crash probability, that is, the relative number of crashes normalized by a number of launches throughout a certain period. The failure rate for each launching site varies from $4 \%$ to $10 \%$ and decreases in general with the growth of launch number. For the whole period of operation the largest rate of failures occurred at Kapustin Yar (16\%), thereafter at Cape Canaveral (10\%), Baikonur (8.5\%), Vandenberg (8.5\%), Kourou (7\%), and the lowest rate of failures was at Plesetsk (4\%).

We will estimate the dependence/independence of an accident occurrence and a parameter under the study with the following statistical approach. To come up with a measure of their dependence, we will use the $\chi^{2}$ test [13]. In this particular case, one of the two variables is the Boolean indicator of whether or not an incident happened, and the other variable is a parameter. Our null hypothesis is the assumption that this parameter and launch failures are independent. Given marginal frequencies of a particular parameter and launch failures, we can calculate (based on that independence assumption) the theoretical frequencies of failures for each parameter value. Next, we compare these theoretical frequencies with the actual frequencies observed. The $\chi^{2}$ test is used to decide if the deviation of the observed 


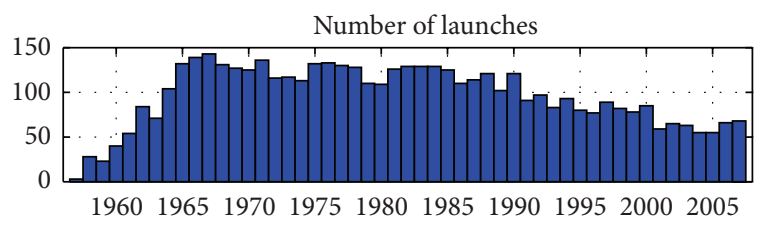

(a)

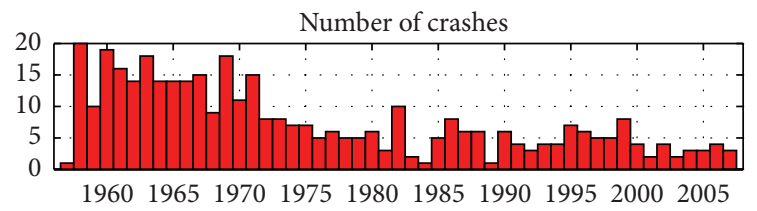

(b)

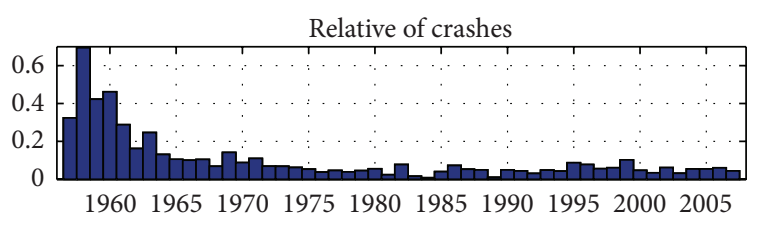

(c)

FIGURE 3: Yearly distributions of the number of launches, launch failures, and relative number of crashes for all world-wide launches from 1957 till 2007. Relative number of crashes is the number of crashes per year normalized by the number of total launches that year.

frequencies from the theoretical ones is large enough to reject the null hypothesis. Two random variables are considered independent if the observed frequencies are close to the expected theoretical frequencies. The Pearson $\chi^{2}$-criterion checks whether the summary deviations of the failure rate from the expected rate are within the tail $\alpha$ of the event distribution, where the apriori significance level $\alpha$ has been chosen to be 0.05 . Additionally, we estimate the attained level of significance ( $P$-value), which is the probability to get a larger statistical criterion than for a given sample. The larger is $P$-value, the higher is the probability that null-hypothesis is correct. If the $P$ value is smaller than the chosen apriori significance level $\alpha$, the null hypothesis must be rejected.

The statistical analysis of the failure rate dependence on various technical and geophysical parameters, launcher type, season, magnetic activity, and so forth, has been performed in a similar way. We have applied also the method of superposed epoch analysis which gives the possibility to estimate relatively short-period variations around the moment of a failure.

3.1. Statistics of Failures for Different Types of Launchers. Since the onset of the space era, more than 60 types of launch vehicles have been used [14]. For the statistical analysis, we select only those launchers that are widely used (not less than 100 launches). Differences between modifications of the same type of launchers have been neglected (e.g., all launch vehicles Ariane-1, Ariane-2, and so forth, have been considered as just Ariane, the rocket Kosmos assumes Kosmos-11 K65, Kosmos$65 \mathrm{~S} 3$, etc.). The comparison of the failure rate for various types of launchers is shown Figure 4.

We will estimate dependence/independence of the accident occurrence on a launcher type. In this case, one of two

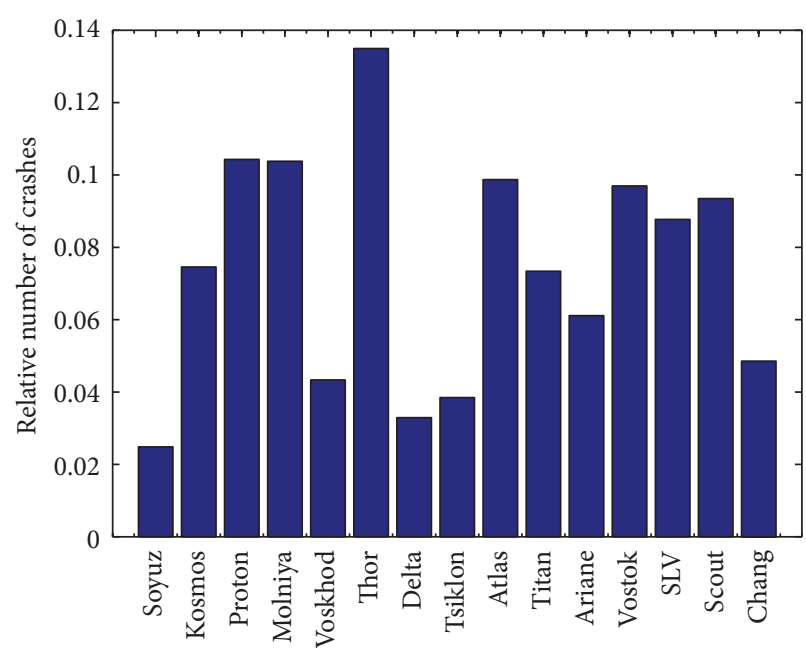

FIGURE 4: Relative number of crashes (the number of crashes normalized on a number of launches) for various types of launchers.

statistical variables is the Boolean indicator of whether or not an incident happened, and the other variable is the launcher type. From 4333 launches under examination 295 (6.8\%) of them failed. If a failure rate does not depend on a type of launcher, then in each group this rate must be $6.8 \%$. However, Pearson $\chi^{2}$-criterion indicates a relation between the failure rate and launcher type. However, this criterion does not show which particular group of launchers is more vulnerable to failures. Attained level of significance $P<10^{-5}$, while $\chi^{2}=$ 120 , hence, the null hypothesis must be rejected. Soyuz and Thor launchers have the largest deviation from the expected $6.8 \%$ failure rate: the failure rate for Soyuz is only $2.5 \%$, and that for Thor is as high as $13 \%$. Proton and Kosmos vehicles also have failure rates nearly 2 times higher than the average one.

We have verified the same null hypothesis for all launchers excluding Soyuz and Thor. For this subgroup, the attained level of significance is less than the apriori chosen $\alpha=0.05$, which means that there are no statistical distinctions between failure risks for the remaining launcher types. Further, this sub-group has been compared with other groups of launchers, where the failure rate dependence on a type might be expected. The obtained $\chi^{2}$-criterion value turns out to be larger than the critical value, thus, it may be concluded that the four preselected launcher groups (Proton, Kosmos, Soyuz, and Thor) indeed differ from other launcher types. Then, we perform a similar exclusive analysis for each of the four groups taking into account the Bonferroni correction factor [15]. The Bonferroni correction is a safeguard against multiple tests of statistical significance on the same data falsely giving an appearance of significance purely by chance. If it is desired that the significance level for the whole family of tests should be $\alpha$, then the Bonferroni correction would be to test each of the individual tests at a significance level of $\alpha / n$, where $n$ is the number of hypotheses to be tested. As a result, we found that for Proton and Kosmos launchers the deviations in the failure rate are statistically insignificant from others. For Soyuz and Thor, the deviations have been proven 


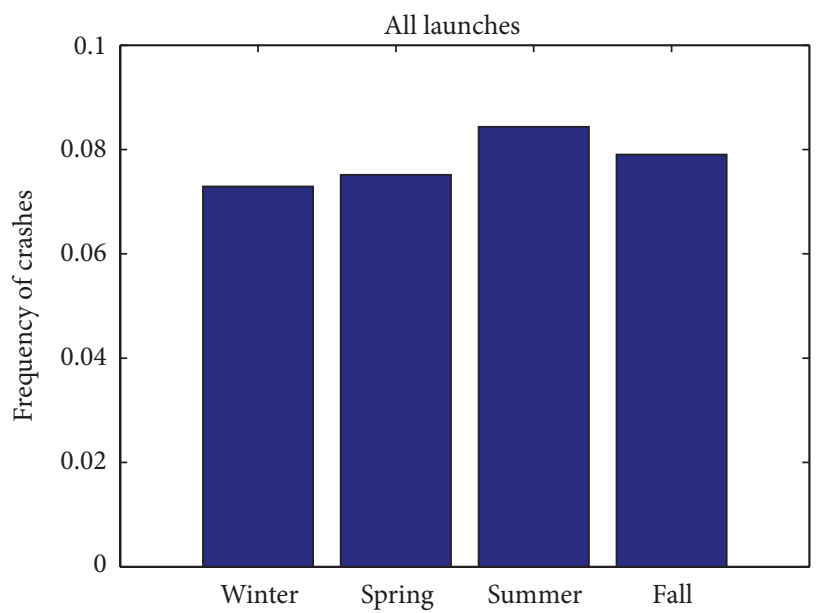

(a)

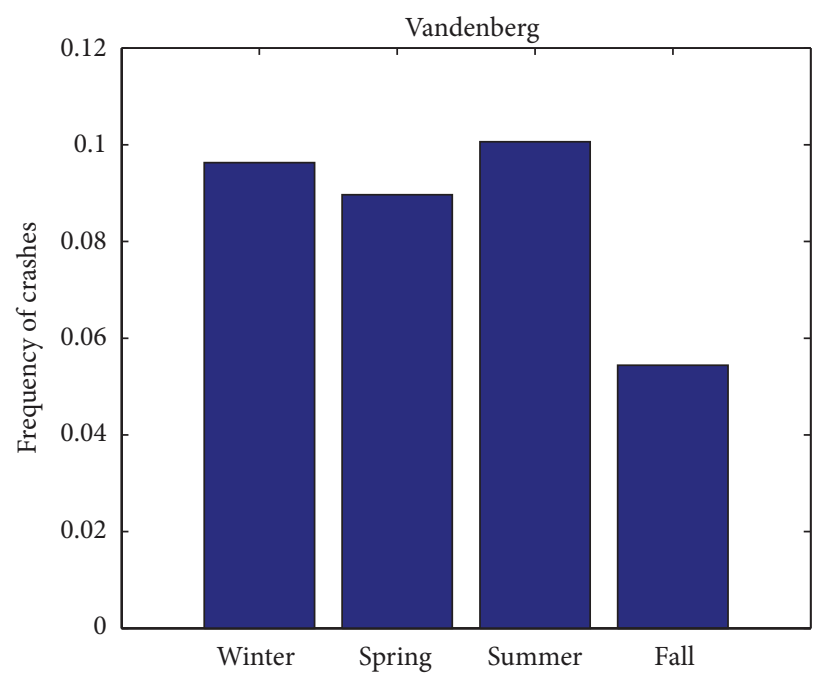

(c)

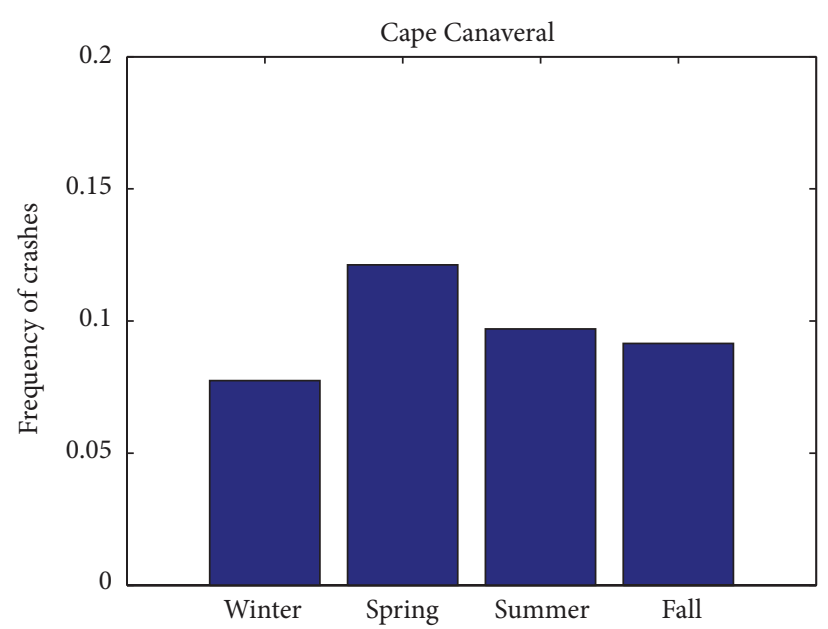

(b)

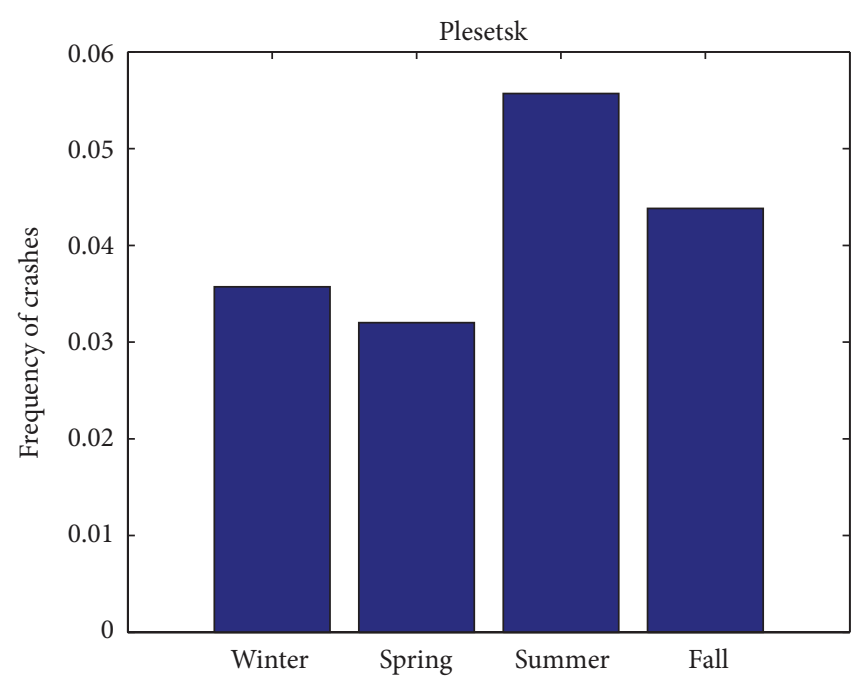

(d)

FIGURE 5: The season distribution of relative launch crashes (the relative number of crashes normalized on a number of launches throughout a certain season): (a) world-wide, (b) Cape Canaveral, (c) Vandenberg, and (d) Plesetsk.

to be statistically significant, so these thrusters are to be considered as most reliable and most risky, correspondingly.

\subsection{Seasonal and Daily Variations of the Launch Crash Probability}

3.2.1. Seasonal Effects. For the examination of seasonal dependence, all launches have been grouped into the winter period (December-February), spring (March-May), summer (June-August), and autumn (September-November). During the 50 years of operation, the seasonal probability distribution of all world-wide launch crashes (Figure 5(a)) is found to be very uniform for all four seasons with a slight increase in summer.

The seasonal dependence of the world-wide failure rate has been validated with the $\chi^{2}$-criterion, where a null hypothesis implies that the failure rate does not depend on the season under the confidence level $\alpha=0.05$. The statistical analysis proves the absence of any seasonal effect: the significance level $P=0.9$, and $\chi^{2}=1.3$.

However, for some individual space ports the seasonal dependence has anomalies. For example, the frequency of crashes at Cape Canaveral seems to be higher in spring than during other seasons (Figure 5(b)). The accident rate at Vandenberg (Figure 5(c)) seems to decrease in autumn as compared with other seasons. At Plesetsk (Figure 5(d)) in summertime, the percentage of emergencies increases $\sim 1.5$ times as compared to other seasons. The seasonal distribution for Baikonur turns out to be flat and is not shown.

The statistical analysis with the use of the $\chi^{2}$-criterion reveals that both the spring peak at Cape Canaveral and autumn minimum at Vandenberg are statistically insignificant $\left(P=0.6, \chi^{2}=1.8\right.$ for Cape Canaveral, and $P=$ $0.5, \chi^{2}=2.5$ for Vandenberg). Thus, the visual impression 


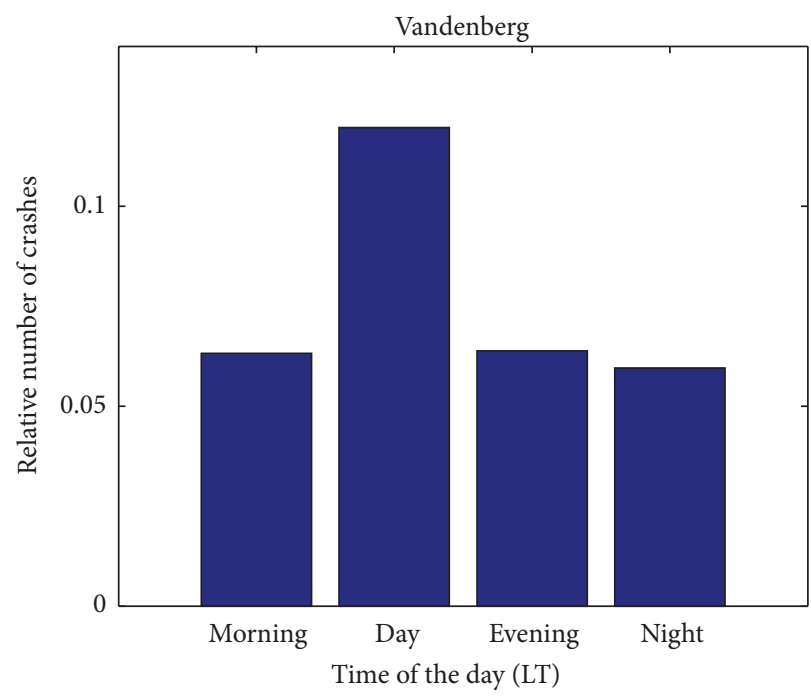

(a)

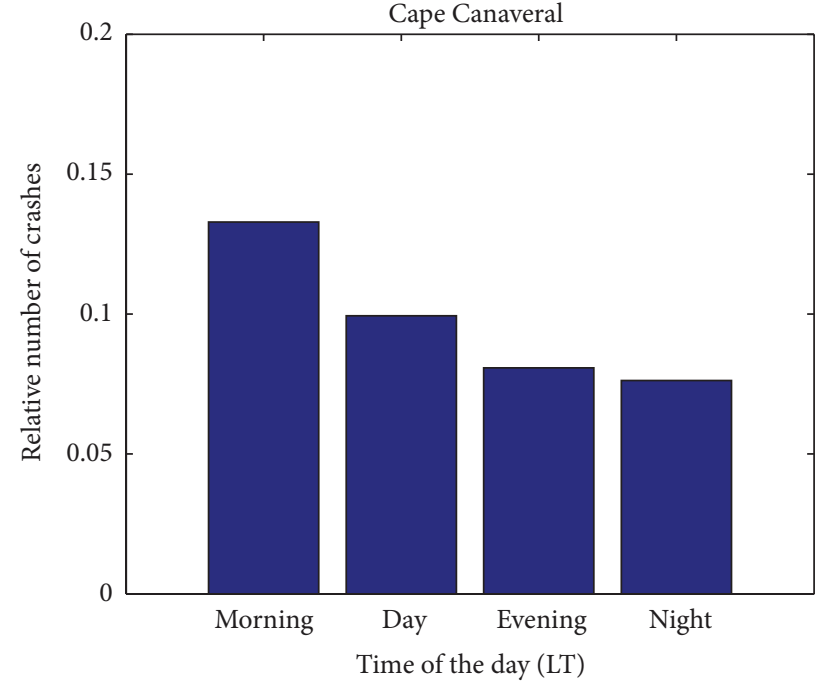

(b)

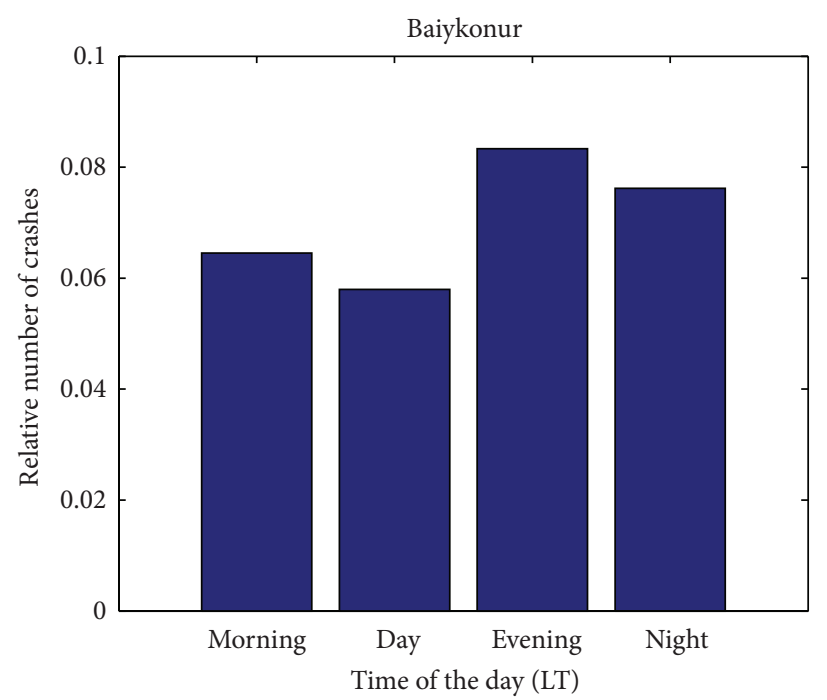

(c)

FIGURE 6: The daily distributions of relative launch crashes at the main space ports: (a) Vandenberg (UT -8 hr), (b) Cape Canaveral (UT $-05 \mathrm{hr}$ ), and (c) Baykonur (UT $+05 \mathrm{hr}$ ) depending on LT sector: morning (LT = 06-11), afternoon (LT = 12-17), evening (LT = 18-23), and night $(\mathrm{LT}=23-05)$.

is not supported by the statistical validation, so the seasonal peaks at these launching sites are statistically insignificant.

The statistical validation with the $\chi^{2}$-criterion shows that the summer maximum at Plesetsk turns out to be near the limits of statistical fluctuations. The probability of the first order error is rather high, $\sim 0.4$, thus, the increase of takeoff failures at Plesetsk in the summer time is very near to the statistical dispersion, or just slightly above it $\left(P=0.2, \chi^{2}=\right.$ 4). Thus, no launching site shows a statistically convincing dependence of the launch failures on a season.

3.2.2. Daily Variations. We have tried to evaluate the diurnal distribution of launch failures, though the time of launch is not known for all events. These daily time distributions of launch crashes at different sites (Vandenberg, Cape Canaveral, and Baykonur) are shown in Figure 6. The events are binned according to their local time (LT) into the following subsets: "morning" (LT = 06-11), "afternoon" (LT = 12-17), "evening" (LT = 18-23), and "night" (LT = 23-05).

It is natural to suppose that the failure rate is to be the same at all local times. However, interesting local peculiarities can be revealed at space ports Canaveral and Vandenberg. The failure rate at Canaveral (Figure 6(b)) has a weak increase in the morning hours, but the $\chi^{2}$-criterion shows that this increase is not statistically significant $\left(P=0.3, \chi^{2}=3.5\right)$. At Vandenberg (Figure 6(a)) during the daytime, the failure rate increases $\sim 2$ times as compared to the rest of the day. This 


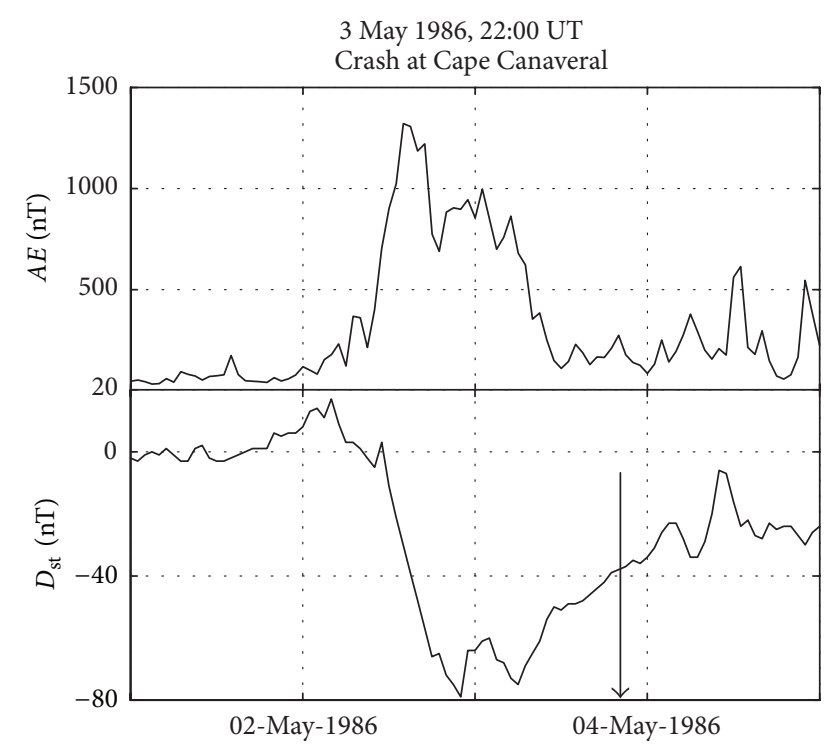

(a)

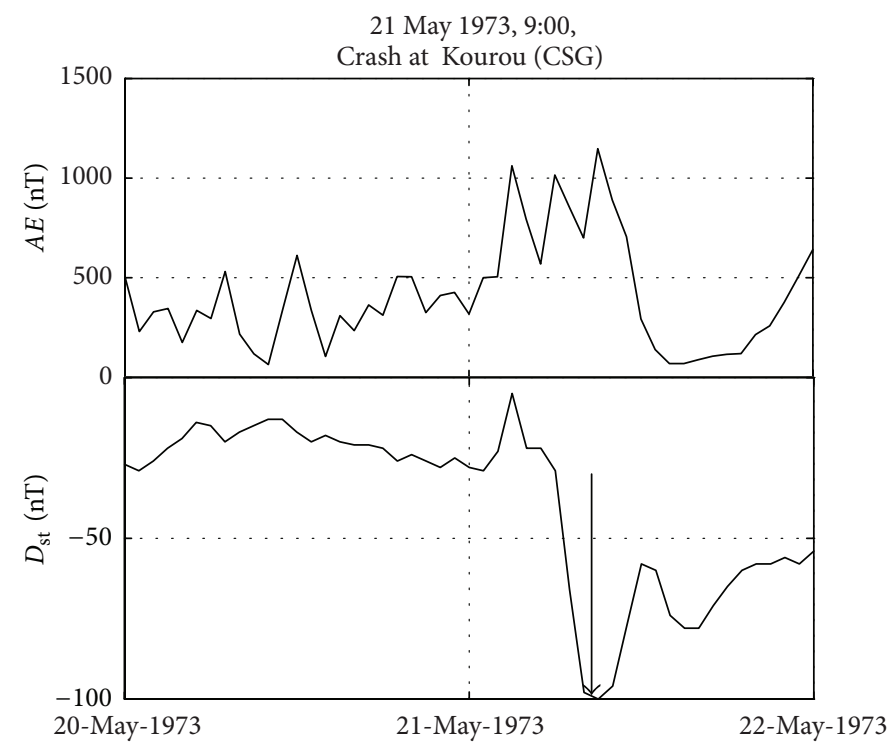

(c)

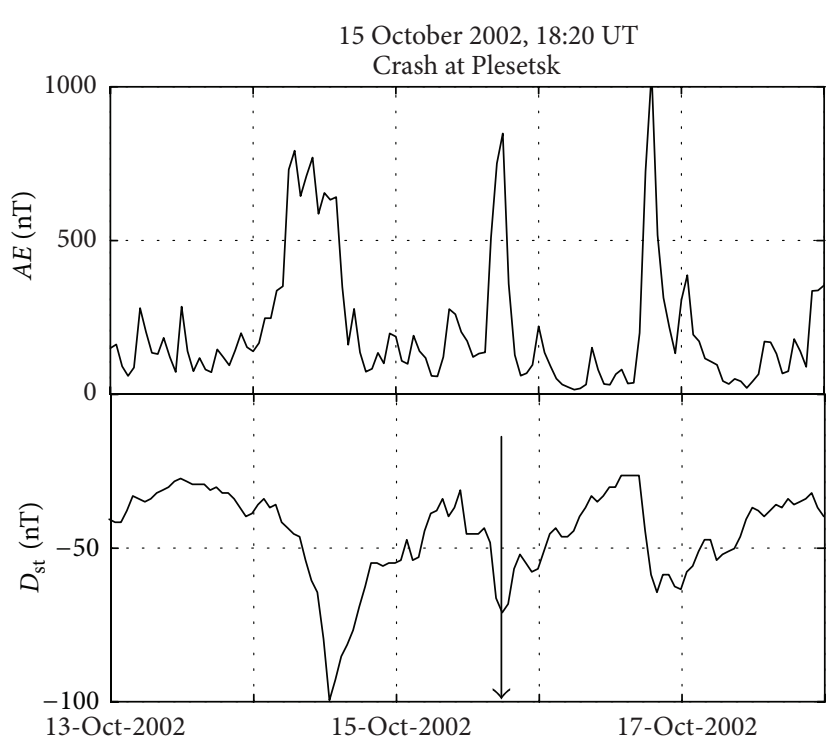

(b)

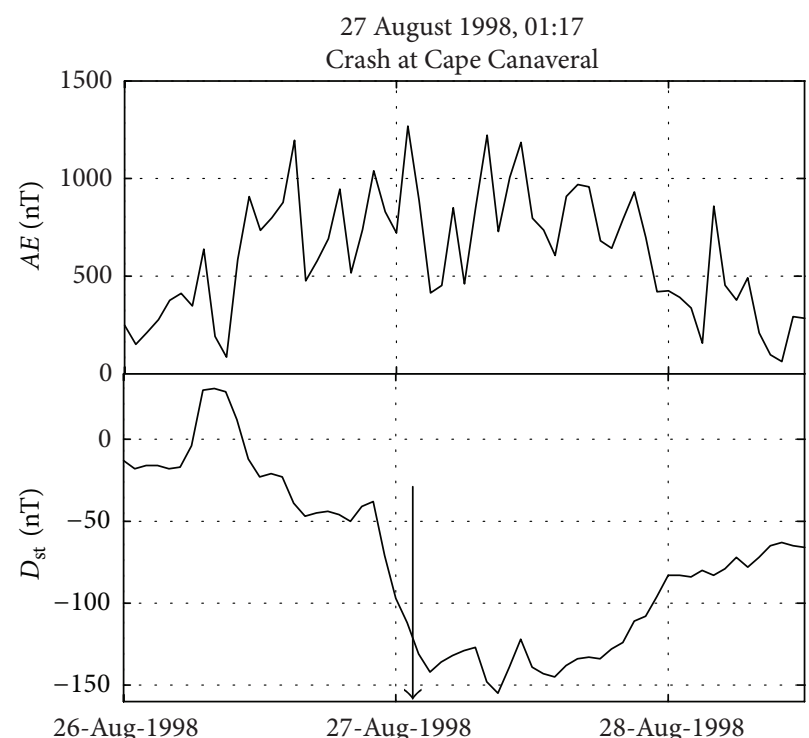

(d)

Figure 7: Examples of launch failures during magnetic storms: (a) rocket Delta at Cape Canaveral on May 02, 1986, (b) rocket Soyuz at Plesetsk on October 15, 2002, (c) rocket Diamant B at Kourou on May 21, 1973, and (d) rocket Delta at Cape Canaveral on August, $27,1998$.

increase turns out to be statistically significant according to the $\chi^{2}$-criterion $\left(P=0.039, \chi^{2}=8.31\right)$. We are not aware of any reasonable explanation for this fact.

\section{Launch Crashes, Solar, and Geomagnetic Activity}

4.1. Example of Launches during Severe Space Weather. A possible relation of launch failures with space weather conditions may result from the fact that $\sim 40 \%$ of failures occurred when during the day before the launch the indices indicated geomagnetic disturbances: $D_{\text {st }}<-50 \mathrm{nT}$ and $A E>500 \mathrm{nT}$. More than half of failures (56\%) occurred when $K_{p}>3$ the day before launch. Nearly $10 \%$ of failures occurred during main and $\sim 20 \%$ during recovery phase of magnetic storm. However, a relationship between the space weather and takeoff failures, if it exists, is not straightforward. During periods of strong space weather disturbances, as characterized by geomagnetic indices, evidence has been found of both successful launches and failures. Figure 7 shows several examples of launch failures during times of disturbed space weather.

The rocket Delta 3914 failure on May 3, 1986 (Figure 7(a)), which prevented the placement into orbit the GOES-G satellite, occurred just after an intense substorm (AE 1300 nT) during moderate, but long-lasting magnetic storm $\left(D_{\text {st }} \sim\right.$ $-80 \mathrm{nT})$. The engine of the third stage accidentally turned on too early because of errors in the electronic system. 
On October 15, 2002 (Figure 7(b)) at Plesetsk the space laboratory Foton-M was launched by the middle-range rocket Sojuz-U. Approximately $30 \mathrm{sec}$ after takeoff, the 400 tons rocket exploded because of an unknown technical error, causing a forest fire and casualties. This crash occurred during a moderate magnetic storm $\left(D_{\text {st }} \sim-70 \mathrm{nT}, A E \sim 800 \mathrm{nT}\right)$. The actual cause of the crash has not been identified.

On May 21, 1973 (Figure 7(c)) during the main phase of a strong magnetic storm $\left(D_{\text {st }} \sim-100 \mathrm{nT}\right)$, the rocket Diamant$\mathrm{B}$ crashed by an unknown reason at the Kourou launching site.

On August 27, 1998 (Figure 7(d)) the rocket Delta-8930 carrying the Galaxy satellite lost radio contact with Canaveral $80 \mathrm{sec}$ after takeoff and fell down into the ocean. This crash occurred during the main phase of a strong magnetic storm $\left(D_{\text {st }} \sim-150 \mathrm{nT}, A E \sim 1200 \mathrm{nT}\right)$. On the preceding day, August 26 , during the solar proton event, the flux of protons with $E>10 \mathrm{MeV}$ reached $J \sim 670(\mathrm{~cm} \cdot \mathrm{s} \cdot \mathrm{str})^{-1}$ and was still highly elevated during the crash.

There are many other examples of launch failures during the main and recovery phases of magnetic storms (not shown): launch failures at Plesetsk on March 28, 1995 and October 15, 1986-a day after a magnetic storm onset; at Baikonur on March 25, 1966, November 25, 2002, July 22, 1971, and December 9, 1982-less than a day after a moderate magnetic storm onset; at Jiquian Space Centre on July 28, 1979; at Centre Spatial Guyanais on September 10, 1982-at the recovery phase of a strong magnetic storm, and so forth.

On the other hand, on July 15, 2000 a strong geomagnetic storm occurred: $D_{\text {st }}$ index reached as low as $-295 \mathrm{nT}$, and other geomagnetic indices were very high $A E \sim 1800 \mathrm{nT}, K_{p} \sim$ 9 [16]. On this date, there were severe accidents onboard various spacecraft, for example, total loss of ASCA satellite, temporary problems with GOES-8,10, ACE, WIND, SOHO, $\mathrm{YOHKOH}$, TRACE, and others [17]. Nonetheless, from the Plesetsk the rocket Kosmos-11K65 M was successfully launched during this period.

4.2. Dependence of the Launch Failures on Solar Activity. The comparison of solar activity, as characterized by yearly averaged Wolf number $\langle R\rangle$, and yearly distributions of the relative number of crashes (i.e., yearly number of failures normalized by the yearly number of launches) for all worldwide launches from 1957 till 2007 is shown in Figure 8. A surprisingly high $(\sim 0.36)$ positive correlation of the relative number of crashes with the average annual level of solar activity can be seen for the entire period from 1957-2007.

However, a careful analysis shows that this high correlation is due mainly to the beginning of the space age: from 1957 till 1975, when the correlation coefficient of the crash probability with $\langle R\rangle$ is high, $\sim 0.69$, whereas the significance level of this correlation is $P=0.0015$. Since the magnitude of $P$ is less than $\alpha=0.05$, this correlation is statistically significant.

For later time intervals, the correlation decreases, and, for the interval 1978-2007, the correlation coefficient becomes -0.26 . The relevant significance level is $P=0.2$, which means that the correlation is lacking. We suggest that this

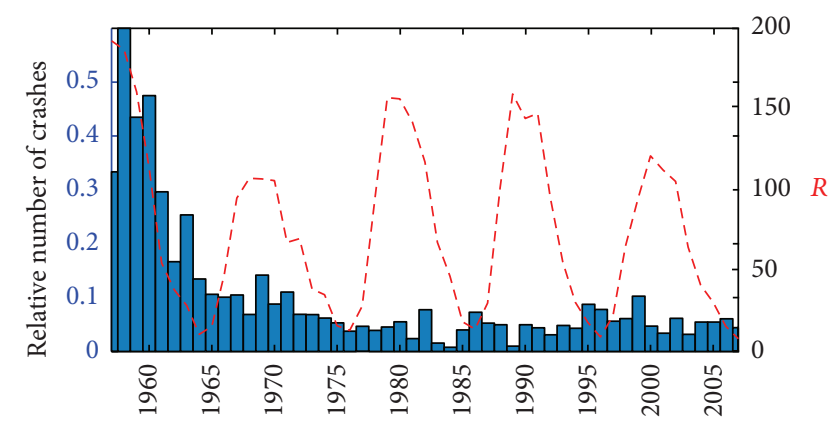

FIGURE 8: The comparison of yearly distributions solar activity, as characterized by sunspot number $\langle R\rangle$ (red curve) and the relative number of crashes for all launches from 1957 till 1975 (blue histogram).

dependence is due to the fact that the beginning of the space age coincided with the solar maximum in 1957, and that in the following years the decrease of failures is mainly attributed to improvements of technology and skill of personnel. Later on, when the failure rate was stabilized at most launching sites, no indications on the solar activity dependence can be seen.

4.3. Geomagnetic Activity Effect. The indices of geomagnetic and auroral activity have been analyzed for the time period around every launch crash. The statistical null hypothesis assumes that the time of launch is random in respect to geomagnetic activity, so launches are to have the Poisson distribution in respect to the geomagnetic indices. Thus, the probability of the launch occurrence during a particular value of geomagnetic index is determined by the intrinsic index distribution only. Indeed, the general statistical distribution of geomagnetic indices and distribution of indices during the failures have turned out to be similar. However, because the index distributions are not normal (rather power law), one cannot apply the parametric methods (e.g., dispersion analysis) [13] for the validation of the relationships between the geomagnetic activity and the failure rate. Only if there is a distinction between the statistical distributions of indices during the events and general statistics, may one assume the possibility of the failure being related to geomagnetic activity.

Because the level of energetic particle fluxes in the terrestrial magnetosphere is considerably determined by the prehistory of the magnetospheric disturbance evolution, we use the maximum value of the geomagnetic indices $K_{p}{ }^{(\max )}$, $A E^{(\max )}$, and $D_{\text {st }}{ }^{(\max )}$ during a 24-hour period before a takeoff as a measure of space weather conditions.

In Table 2 , the attained levels of significance $\left(\chi^{2}\right.$ criterion) are summarized for each geomagnetic index. As a measure of failure probability, the relative number of failures normalized by the number of launches during an analyzed period has been taken. The relative number of world-wide crashes under a given level of $A E^{(\max )}$ index (Figure 9(a)) and $K_{p}{ }^{(\max )}$ index (Figure $9(\mathrm{~b})$ ) is about the same, $\sim 9 \%$, for any interval of the index. Despite the visual impression that there seems to be an enhanced failure rate during moderately 


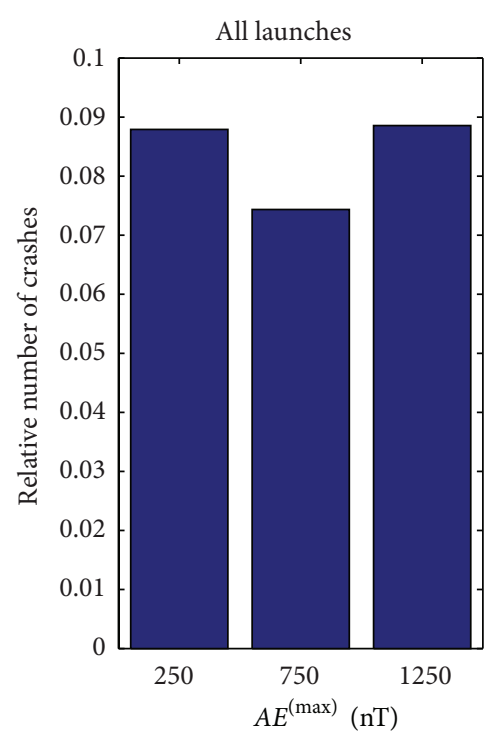

(a)

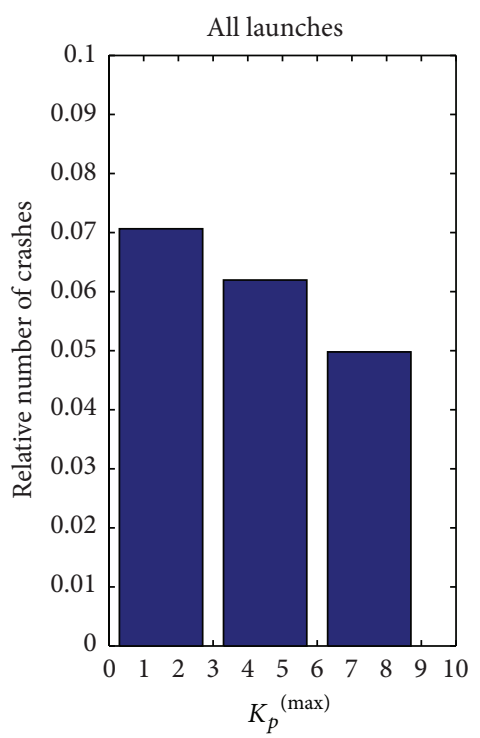

(b)

FIGURE 9: Relative number of crashes for different levels of geomagnetic indices (for maximum value for the previous day) of $K_{p}$ (a) and $A E$ (b).

disturbed storms, $A E^{(\max )}>500 \mathrm{nT}$, the analysis does not reveal a statistically significant distinction between the general sample and the distribution during launch failures. Both for $K_{p}{ }^{{ }^{(\max )}}$ (Figure 9(b)) and $D_{\text {st }}{ }^{(\max )}$ (not shown) the dependence of launch failure on magnetic activity level is statistically insignificant.

Though the total failure rate does not depend on geomagnetic activity, such dependence could be revealed for a particular launch site, because geophysical factors are strongly latitude dependent. Therefore, a possible dependence of the launch failure on geomagnetic activity has been statistically analyzed for each rocket site. The results of the estimated dependence of failures on geomagnetic activity are summarized in Table 2 for the midlatitude sites, Baikonur, Cape Canaveral, and Vandenberg, and the high-latitude Plesetsk site. The detailed analysis for each site is presented below.

4.3.1. Midlatitude Sites: Baikonur, Cape Canaveral, and Vandenberg. The histograms of the relative number of crashes at Baikonur for various intervals of $K_{p}{ }^{(\max )}$ and $A E^{(\max )}$ values are given in Figure 10. The failure probability is pretty much the same for all levels of $A E^{(\max )}$ and $K_{p}{ }^{(\max )}$ values. Some deviations at extreme magnitudes of $A E^{(\max )}$ and $K_{p}{ }^{(\max )}$ indices are not statistically significant (Table 2). Neither does the analysis of failure rate on $D_{\text {st }}$ index reveals any statistically significant relations (not shown). Thus, the failure probability at Baikonur does not depend on geomagnetic activity.

The failure probability at Cape Canaveral increases with the growth in the geomagnetic activity, characterized by $K_{p}^{(\max )}$ (Figure 11(a)) and $A E^{(\max )}$ (Figure 11(b)) indices. The increase of the failure rate at very high values, $K_{p}{ }^{(\max )}>6$ and $A E^{(\max )}>1000$, is statistically significant. Nonetheless, we cannot prove this conclusion with a great confidence,
TABle 2: The attained levels of significance ( $P$-values) for relationships between launch failures at various launch sites and geomagnetic activity (italic data indicate the occurrence of statistically significant relationships if apriori significance level $\alpha$ has been chosen to be 0.05).

\begin{tabular}{lcccc}
\hline \multirow{2}{*}{ Launching site } & \multicolumn{4}{c}{ Geomagnetic indices } \\
& $K_{p}$ & $D_{\text {st }}$ & $A E$ & $P$ \\
\hline Total & 0.31 & 0.82 & 0.32 & - \\
Baykonur & 0.47 & 0.22 & 0.9 & - \\
Canaveral & 0.04 & 0.38 & 0.02 & 0.03 \\
Vandenberg & 0.73 & 0.052 & 0.04 & - \\
Plesetsk & 0.27 & 0.76 & 0.8 & 0.04 \\
\hline
\end{tabular}

"-": relationship with the index was not checked ( $\chi^{2}$-criterion).

because the sample number at high level of geomagnetic disturbances is not representative, only 7 events.

Therefore, the power of any statistical criterion is not very high, $\sim 55 \%$, so the probability to reject wrongly the null hypothesis is high. Rather surprisingly, the statistical-ly significant relationships between the launch failures at Cape Canaveral with the auroral power index $P^{(\max )}$ have been revealed: the risk of failure increases for $P^{(\max )}>125 \mathrm{GW}$. However, a similar distribution in respect to the $D_{\text {st }}$ index does not reveal any statistically significant effects (not shown). Thus, a statistically nonnegligible correlation between failure rate at Cape Canaveral and geomagnetic activity manifests itself only for indices mostly corresponding to the auroral and the middle latitude activity $(A E, P$, and $\left.K_{p}\right)$, but not to the near-equatorial disturbances $\left(D_{\text {st }}\right)$.

A similar situation is observed at Vandenberg. The relative number of failures at this launch site shows a peak at high $A E^{(\max )}$ indices, 1000-1500 nT (Figure 12(a)), and 


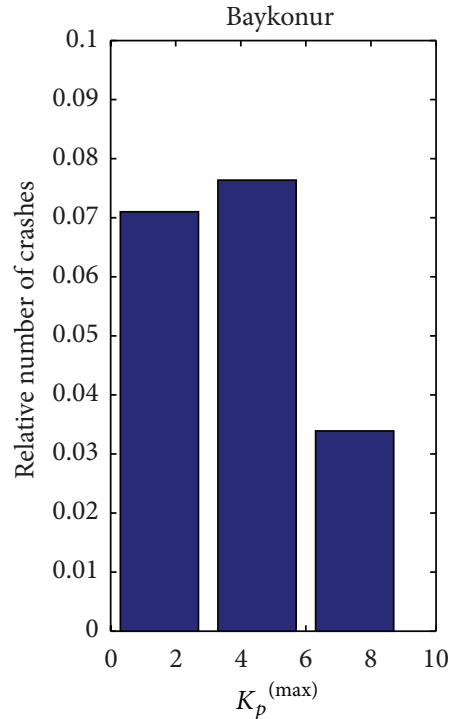

(a)

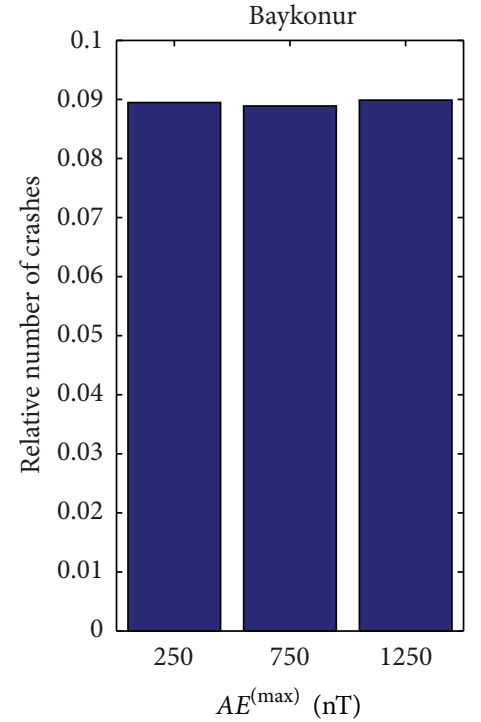

(b)

Figure 10: Relative number of crashes for different levels of geomagnetic indices $K_{p}$ (a) and $A E$ (b) at Baykonur.

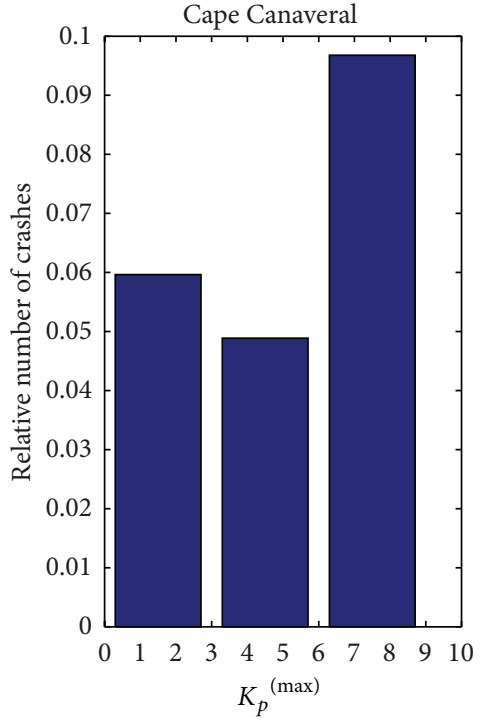

(a)

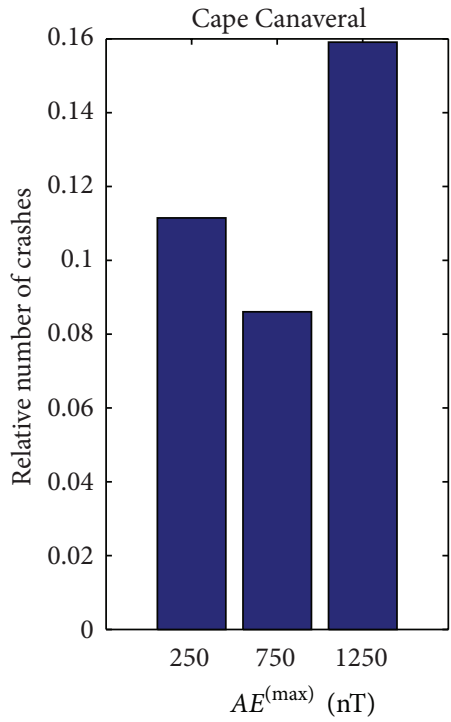

(b)

Figure 11: Relative number of crashes for different level of geomagnetic indices $K_{p}(\mathrm{a})$ and $A E(\mathrm{~b})$ at Cape Canaveral.

this peak turns out to be statistically significant. However, other indices, $K_{p}$ (not shown) and $D_{\text {st }}$ (Figure 12(b)), do not demonstrate any dependence of the launch failures on the geomagnetic activity. At the same time, the increase of the failures at Vandenberg at high $A E^{(\max )}$ is due to 5 events only.

4.3.2. High-Latitude Space Port: Plesetsk. The annual mean number of crashes at the high-latitude space port Plesetsk before 1993 varied from 1 to 3 with the average number of launches being about 50 per year (Figure 13). While the number of launches at Plesetsk is the highest as compared with other launching sites, the general accident rate here is the lowest among all the launching sites (e.g., 2 times less than at Baikonur). From 1966 to 1975, the percentage of crashes steadily decreased, and, up to 1976, the percentage of crashes reached $\sim 2 \%$ per year. Since 1993, the number of launches per year decreased $(<20)$, but at the same time the number of crashes practically remained the same, which resulted in the growth of the relative number of accident risk. 


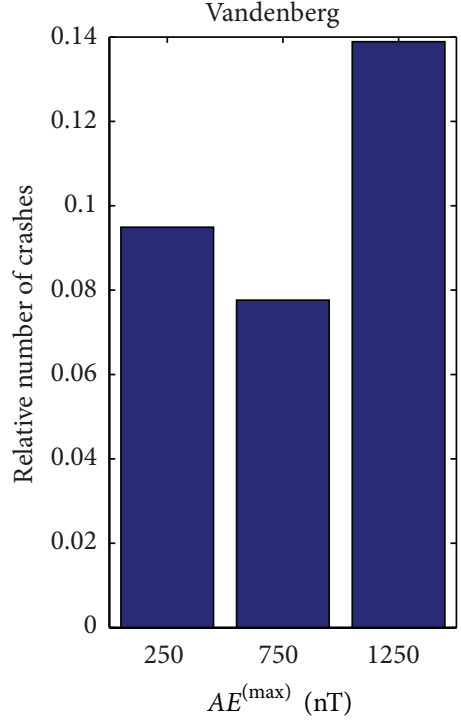

(a)

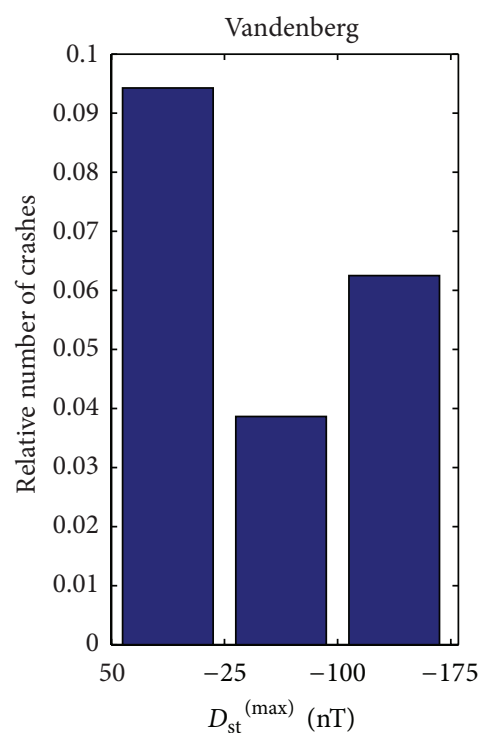

(b)

FIGURE 12: Relative number of crashes for different levels of geomagnetic indices $A E$ (a) and $D_{\text {st }}$ (b) at Vandenberg.

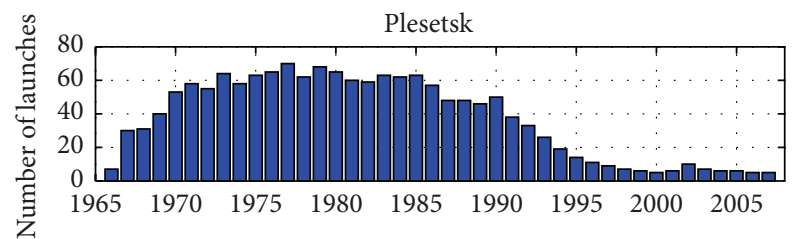

(a)

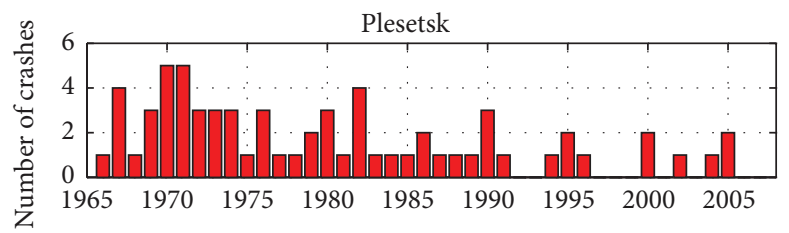

(b)

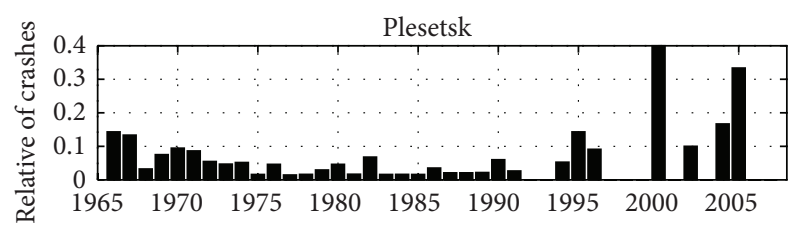

(c)

FIGURE 13: The yearly mean number of launches, crashes, and relative number of crashes (upper to lower panel) at the high-latitude space port Plesetsk from 1966 till 2007.

The relative percentage of emergencies (probability of crash) for Plesetsk is rather stable in time despite the fact that the number of launches has decreased and performance of rockets and take-off facilities has improved. We suggest that the reason for this feature may partly be due to the highlatitude location of Plesetsk. The initial trajectories of rockets launched from Plesetsk go through the auroral zone, where geomagnetic activity effects are major.
Comparison of each launch failure with the geomagnetic activity has shown that $\sim 60 \%$ of failures took place when the hourly $A E$ index exceeded $400 \mathrm{nT}$. The distribution of the relative number of launch failures in respect to geomagnetic indices $D_{s t}, A E$, and $K_{p}$ is shown in Figures 14(a), 14(b), and 14(c). Additionally, a similar histogram has been produced for the auroral $P$ index, characterizing total power input by auroral particles to the northern polar region (Figure 14(d)). The statistical analysis of the failure rate dependence on various indices, $D_{\text {st }}$ (Figure 14(a)), $K_{p}$ (Figure 14(b)), $A E$ (Figure 14(c)), and auroral particle index $P$ (Figure 14(d)), rejects the null hypothesis about the independence of launch failures on these indices. Thus, there is a tendency of a failure rate increase at Plesetsk at higher levels of geomagnetic activity and auroral particle precipitation.

However, the power of statistical conclusions due to limited statistics is not high, so there is still a chance to reject incorrectly the null hypothesis. Separating the geomagnetic activity into two intervals, quiet $\left(A E \leq 400 \mathrm{nT}, K_{p} \leq 3, D_{\text {st }} \geq\right.$ $-50 \mathrm{nT})$ and disturbed ( $\left.A E>400 \mathrm{nT}, K_{p}>3, D_{\mathrm{st}}<-50 \mathrm{nT}\right)$, we found no statistically significant distinctions between quiet and disturbed conditions. If the geomagnetic activity can influence the launch failure rate, then there probably must be a threshold level for such an impact. Because of limited statistics, we cannot estimate reliably this threshold, but may suggest that it should be $A E \sim 1000$ nT.

\subsection{The Relationship of Launch Failures with High-Energy Particle Fluxes}

4.4.1. Launch Crashes and Solar Proton Events. A launch failure may be caused in principle by the burst of solar proton events. Effect of energetic particle events on rocket functioning depends on the type of orbit. Boscher et al. [18] estimated that the risk of failure for ARIANE 5 launch into 


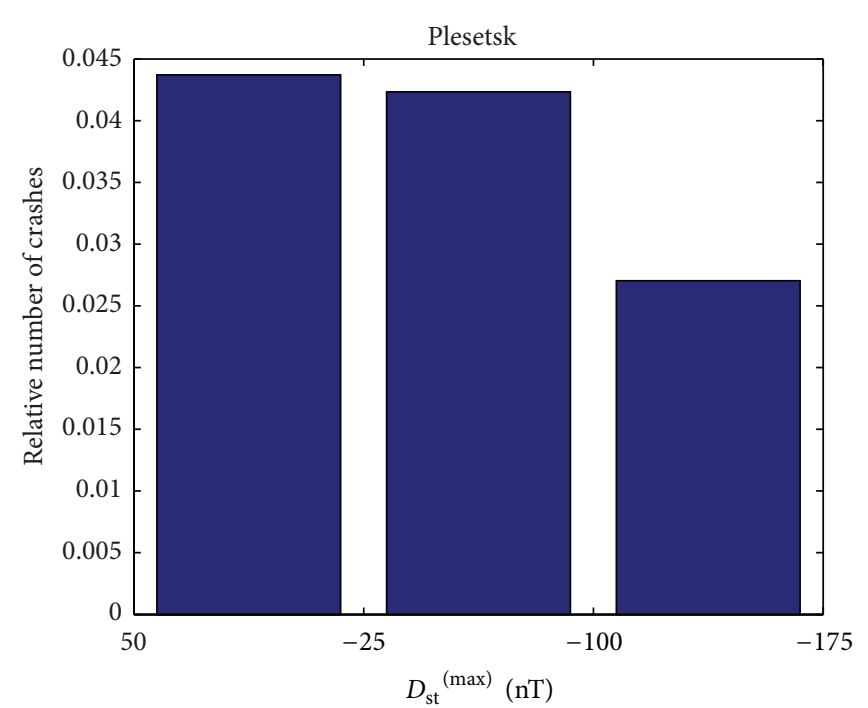

(a)

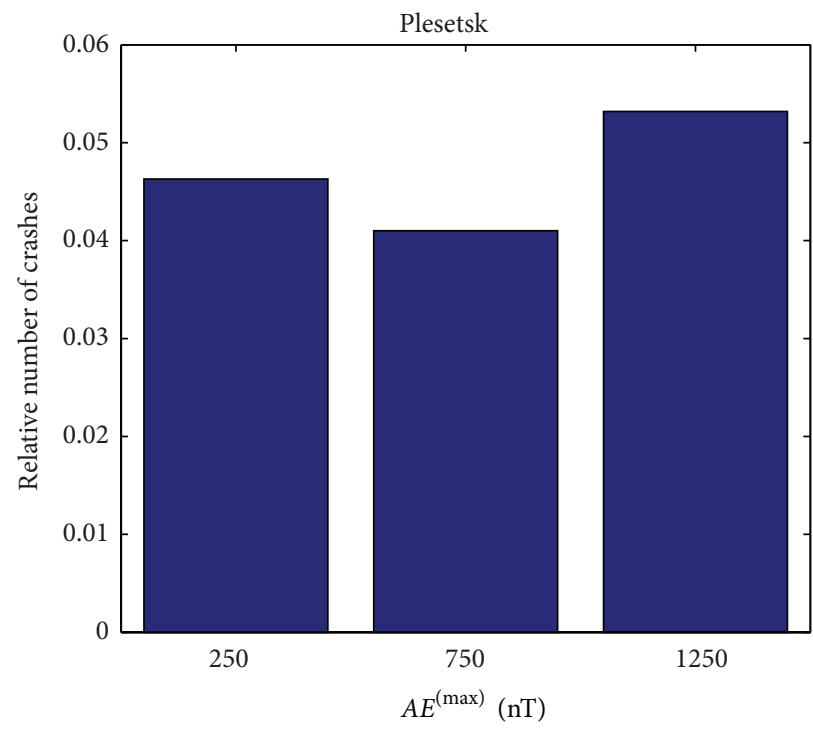

(c)

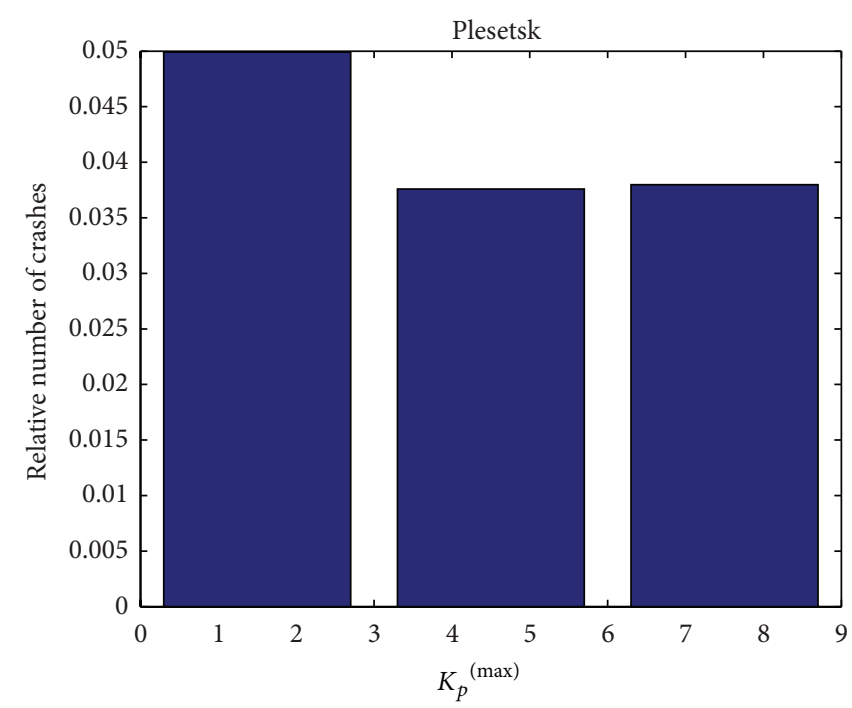

(b)

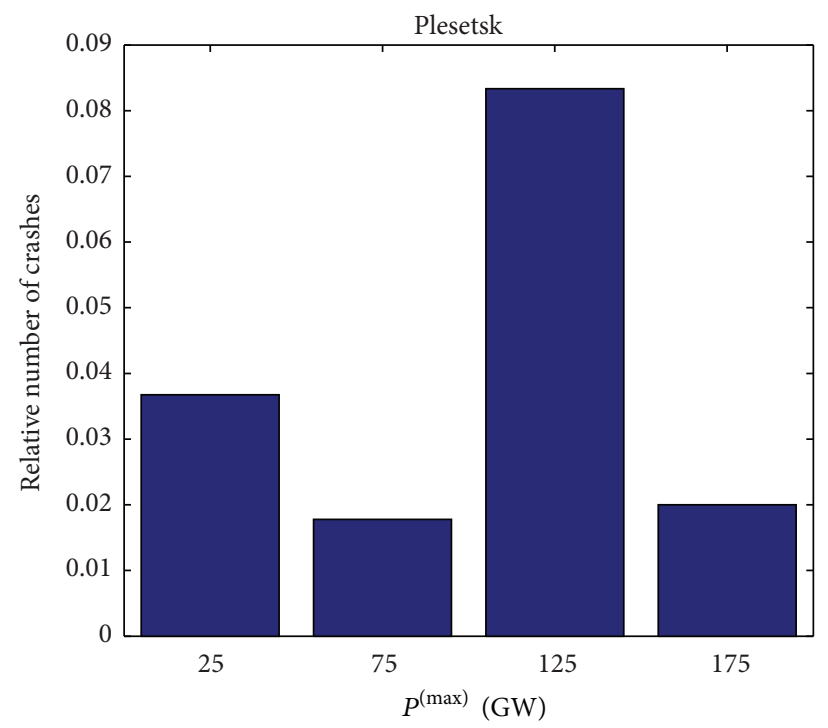

(d)

FIGURE 14: Relative number of crashes for different levels of geomagnetic indices at Plesetsk: (a) $D_{\text {st }}$; (b) $K_{p}$; (c) $A E$; (d) auroral power index $P$.

geostationary orbit is insignificant, but it is increased by a factor of 200 for the launch into sun-synchronous orbit, and by a factor of 10 for a launch into geostationary transfer orbit. However, the overall probability of failure still was estimated to be below the target values (typically 0.02 ) with a possible exception of launch during a solar energetic proton event.

We have verified statistically the possibility of the hazardous impact of solar proton events on launches with the superposed epoch method. In this method, the instant of a launch failure has been taken as a zero reference moment, and variations of particle fluxes have been averaged according to this moment. The proton flux rate with $E>4 \mathrm{MeV}$ measured by IMP averaged over all failed launch events at Cape Canaveral and Baykonour in the 5 days interval around the moment of launch is shown in Figure 15. Though the superposed epoch method demonstrates the occurrence of the intensity peak 1 day before the launch at Cape Canaveral (Figure 15(a)) and the same day at Baykonour (Figure 15(b)), a statistical analysis does not prove a correspondence between these peaks and launch failures. The averaged superposed plots for all successful launches do not deviate noticeably from the plot for failed launches (dashed line). Moreover, the magnitudes of these peaks are less than the root mean squared deviation for given samples.

In no proton energy channels (from $1 \mathrm{MeV}$ to $60 \mathrm{MeV}$ ), any statistically significant effect was observed. This dependence is rather flat and does not show any increase of solar proton intensity during or just before the failure. The same result was obtained for Plesetsk, Vandenberg, and for all crashes in total (not shown). Thus, we may conclude that there are no statistically reliable relationships between solar proton flux intensities and the studied launch failures. 


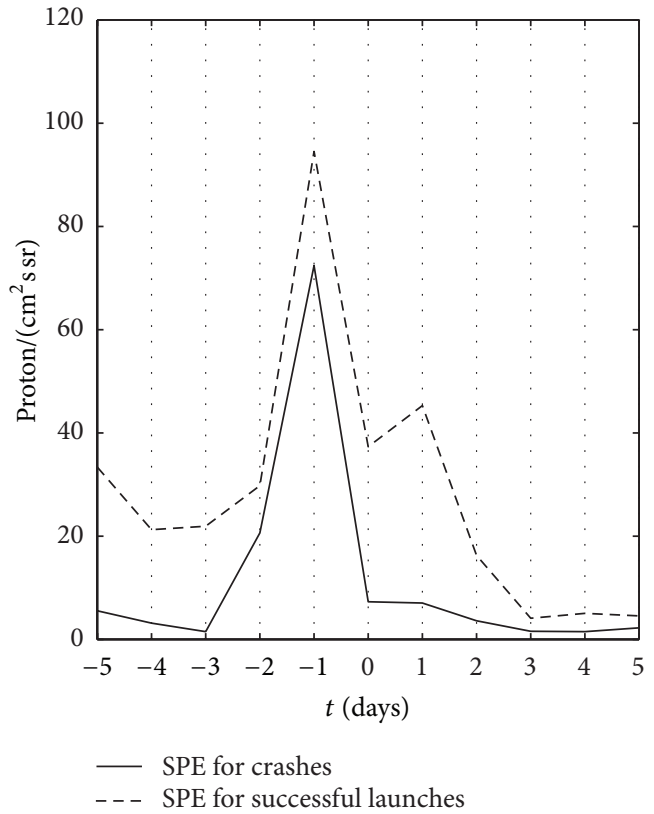

(a)

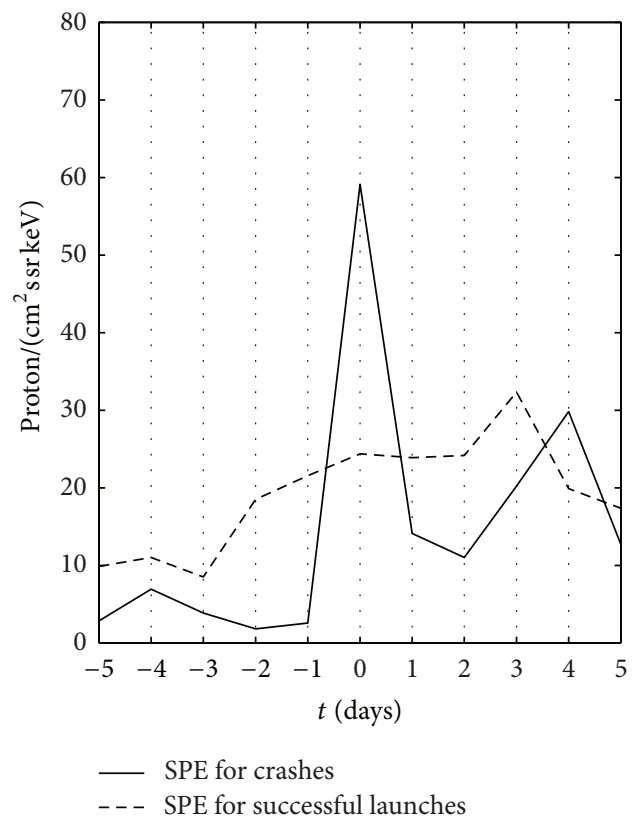

(b)

FIGURE 15: The proton flux rate with $E>4 \mathrm{MeV}$ averaged over crash events in the 5 days interval around the moment of launch: (a) Cape Canaveral; (b) Baikonur.

4.4.2. Launch Crashes at Site Plesetsk and High-Energy Electron Fluxes. The fluxes of magnetospheric electrons with relativistic energies are known to enhance up to 2-3 orders of magnitude at the recovery phase of magnetic storms. Therefore, it might be supposed that the precipitation of relativistic electrons could exert a hazardous impact on rockets launched from high-latitude site, such as Plesetsk. To validate this possibility, we have correlated the high-energy electron fluxes at geostationary orbit with launch crashes at high-latitude site Plesetsk. However, this study, similar to the high-energy protons, has not revealed a statistically reliable correlation (not shown). Although from the total number of 263 at Plesetsk site during a period (since 1990) with available magnetospheric electron data only 14 failed. Probably, such a low statistics is not sufficient for statistically reliable estimates.

\section{Discussion and Conclusions}

The statistical comparison of launch crashes at different space ports with geophysical factors is performed using a big database, that includes information about all rocket launches occurring in the world in the time interval from 1957 to 2007. Attention is given to the largest space ports: Plesetsk, Baykonur, Cape Canaveral and Vandenberg. The main results of this study are as follows.

(i) The accident rate is found to be different for various types of launchers. The failure rate for "Soyuz" is least and is highest for "Thor."

(ii) There are no statistically reliable seasonal effect in the launch failure probability at any sites. The earlier noticed increase of the failure rate at Plesetsk $\sim 1.5$ times in the summertime [12] is not supported by the $\chi^{2}$-criterion.

(iii) For most sites, the failure risk does not depend on the time of the day. Only at Vandenberg, the failure rate is statistically higher during the day time by an unknown reason.

(iv) Solar activity, as characterized by the sunspot number $\langle R\rangle$, does not influence the launch failure. There is no statistically significant influence of solar proton events on failure risk.

(v) Statistically non-negligible relationships between the failure rate and geomagnetic and auroral activity, as characterized by indices $A E, P$, and $K_{p}$, have been revealed at Cape Canaveral, Vandenberg, and Plesetsk.

However, additional validation with the use of nonparametric criterion $\left(\chi^{2}\right)$ and splitting of all the events into disturbed/quiet conditions does not reveal any statistically significant distinctions in the failure probability. Because of rather limited statistics, especially during extreme values of the space weather parameters, the statistical power of estimates is not very high, about $50-60 \%$. Thus, though the tendency of the geomagnetic activity impact on launches at Plesetsk, Cape Canaveral, and Vandenberg is statistically significant, it cannot be confirmed with a high accuracy.

A possible mechanism of space weather impact on rocket launches may be related to various factors. At higher altitudes, high-energy particle precipitation could influence the functioning of the electronic control systems of the launcher. For example, energetic or relativistic electrons can produce 
charging of elements of a rocket in a similar way as of magnetospheric satellites [6]. The intense electric currents during auroral disturbances in the region of the launch trajectory may influence the elements of the launch control system.

The possible mechanism of an indirect space weather impact on rocket launches may be related to disturbances in atmospheric electricity. At the moment of takeoff, a rocket can obtain a substantial spatial charge and considerable electric potential (from $10^{3}$ up to $10^{5} \mathrm{~V} / \mathrm{m}$ for various journey legs) [19]. Increase of electric field intensity can be accompanied by discharges. Electrification of the vehicle depends on electrical conditions in the atmosphere and presence of thunderstorm structures. Also, along the takeoff trajectory the high-altitude atmospheric discharges well above thunderclouds, accompanied by bursts of accelerated relativistic electrons and $\gamma$-rays [20], may be of potential hazards to space missions during the ascent and descent phases.

Interaction of the charged launcher and its engine waste with the conducting ionosphere can result in unexpected effects which are not clearly understood yet. Special experiments (e.g., "Waterhole") showed that injection of combustion materials into the ionospheric plasma results in a fast "sweep" of plasma and generation of intense electrical and magnetic impulses, excitation of turbulence, and stimulation of electron precipitation $[6,21,22]$. It is possible that these effects adversely affect rocket electronic systems.

The results presented in this paper suggest that a more thorough study of space weather effects on launcher systems, especially in the high-latitude regions, should be continued in order to improve the knowledge about the relationship between rocket launch crashes and geophysical parameters. Though the possible number of critical situations during launch and space flight related to the space weather is not very high as compared with general statistics, even a single event can cause huge financial losses. Even a relatively small number of crashes during geomagnetic disturbances are worthy to pay attention to and the problem of the influence of space weather upon launch vehicles and its onboard equipment should be studied in a greater detail. In view of the high costs associated with delaying launch, and possibly missing launch windows, only a nowcast could provide a sufficiently reliable service. Thus, space weather real-time monitoring and prediction could become an important issue in the optimization of launch procedures.

\section{Acknowledgments}

This study was supported by INTAS YSF Grant 05-109-4661 (NR) and Program 22 of the Russian Academy of Sciences (VP).

\section{References}

[1] R. B. Horne, Benefits of a space weather programme, ESA Space Weather Programme Study, BAS Contract 300738, ESA ITT AO/1-3353/99/NL/SB, 2001.
[2] D. N. Baker, J. H. Allen, S. G. Kanekal, and G. D. Reeves, "Disturbed space environment may have been related to pager satellite failure," Eos, Transactions American Geophysical Union, vol. 79, no. 40, pp. 477-483, 1998.

[3] D. N. Baker, "The occurrence of operational anomalies in spacecraft and their relationship to space weather," IEEE Transactions on Plasma Science, vol. 28, no. 6, pp. 2007-2016, 2000.

[4] D. F. Webb and J. H. Allen, "Spacecraft and ground anomalies related to the October-November 2003 solar activity," Space Weather, vol. 2, no. 3, 2004.

[5] N. Iucci, A. E. Levitin, A. V. Belov et al., "Space weather conditions and spacecraft anomalies in different orbits," Space Weather, vol. 3, no. 1, 2005.

[6] V. Pilipenko, N. Yagova, N. Romanova, and J. Allen, "Statistical relationships between satellite anomalies at geostationary orbit and high-energy particles," Advances in Space Research, vol. 37, no. 6, pp. 1192-1205, 2006.

[7] N. V. Romanova, V. A. Pilipenko, N. V. Yagova, and A. V. Belov, "Statistical correlation of the rate of failures on geosynchronous satellites with fluxes of energetic electrons and protons," Cosmic Research, vol. 43, no. 3, pp. 186-193, 2005.

[8] D. H. Boteler, R. J. Pirjola, and H. Nevanlinna, "The effects of geomagnetic disturbances on electrical systems at the Earth's surface," Advances in Space Research, vol. 22, no. 1, pp. 17-27, 1998.

[9] E. G. Stassinopoulos, C. A. Stauffer, and G. J. Brucker, "A systematic global mapping of the radiation field at aviation altitudes," Space Weather, vol. 1, no. 1, 2003.

[10] G. Siscoe, "The space-weather enterprise: past, present, and future," Journal of Atmospheric and Solar-Terrestrial Physics, vol. 62, no. 14, pp. 1223-1232, 2000.

[11] C. Kunstadter, "Space insurance experience and outlook: a statistical review of volatility," in Presentation at the Federal Aviation Administration's Commercial Space Transportation Advisory Committee (FAA COMSTAC '05), 2005.

[12] N. V. Romanova, V. A. Chizhenkov, and V. A. Pilipenko, "Possible relation of emergencies during spacecraft launches from the Plesetsk site to high-latitude geomagnetic disturbances," Geomagnetism and Aeronomy, vol. 49, no. 1, pp. 104-109, 2009.

[13] R. L. Plackett, "Karl Pearson and the Chi-Squared test," International Statistical Review, vol. 51, no. 1, pp. 59-72, 1983.

[14] C. Behrens, "Space launch vehicles: government activities, commercial competition, and satellite exports," Tech. Rep., Congressional Research Service, Washington, DC, USA, 2006.

[15] E. Paulson, "On the comparison of several experimental categories with a control," Annals of Mathematical Statistics, vol. 23, pp. 239-246, 1952

[16] R. Tripathi and A. Mishra, "Occurrence of severe geomagnetic storms and their association with solar-interplanetary features," in Proceedings of the ILWS Workshop on Solar Influence on the Heliosphere and Earth's Environment, Goa, India, February 2006.

[17] J. H. Allen, "Historical and recent solar activity and geomagnetic storms affecting spacecraft operations," in Proceedings of the Government Microcircuit and Applications Conference (GOMAC '02), Monterey, Calif, USA, March 2002.

[18] D. Boscher, J. L. Bougeret, J. Breton, P. Lantos, J. Y. Prado, and M. Romero, Space Weather Final Report from the French Evaluation Group on Needs, European Space Agency, ESTEC, Noordwijk, The Netherlands, 1999. 
[19] D. S. Hazen, W. P. Roeder, B. F. Boyd, J. B. Lorens, and T. L. Wilde, "Weather impact on launch operations at the eastern range and kennedy space center," in Proceedings of the 6th Conference on Aviation Weather Systems, pp. 270-275, January 1995.

[20] T. Neubert, M. Rycroft, T. Farges et al., "Recent results from studies of electric discharges in the mesosphere," Surveys in Geophysics, vol. 29, no. 2, pp. 71-137, 2008.

[21] M. C. Kelley, U. V. Fahleson, G. Holmgren, R. Bostrom, P. M. Kintner, and E. Kudeki, "Generation and propagation of an electromagnetic pulse in the Trigger experiment and its possible role in electron acceleration," Journal of Geophysical Research, vol. 85, pp. 5055-5060, 1980.

[22] A. W. Yau and B. A. Whalen, "Auroral perturbation experiments," Advances in Space Research, vol. 8, no. 1, pp. 67-77, 1988. 

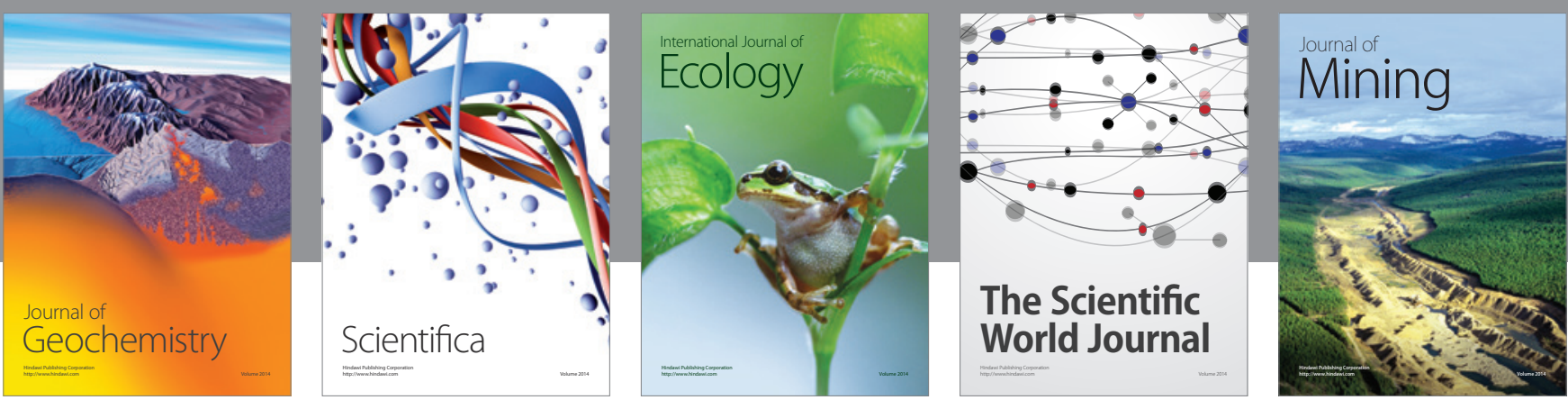

The Scientific World Journal
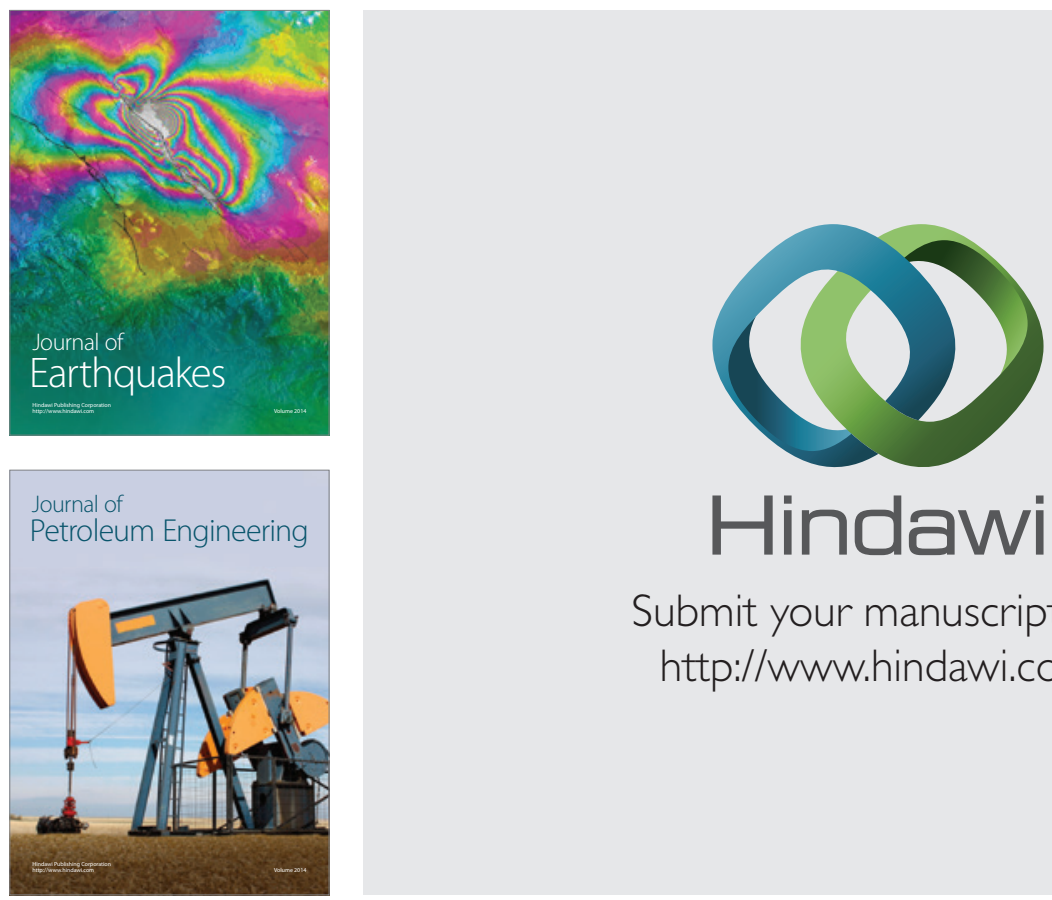

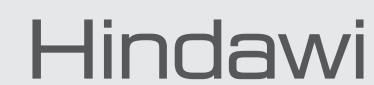

Submit your manuscripts at

http://www.hindawi.com
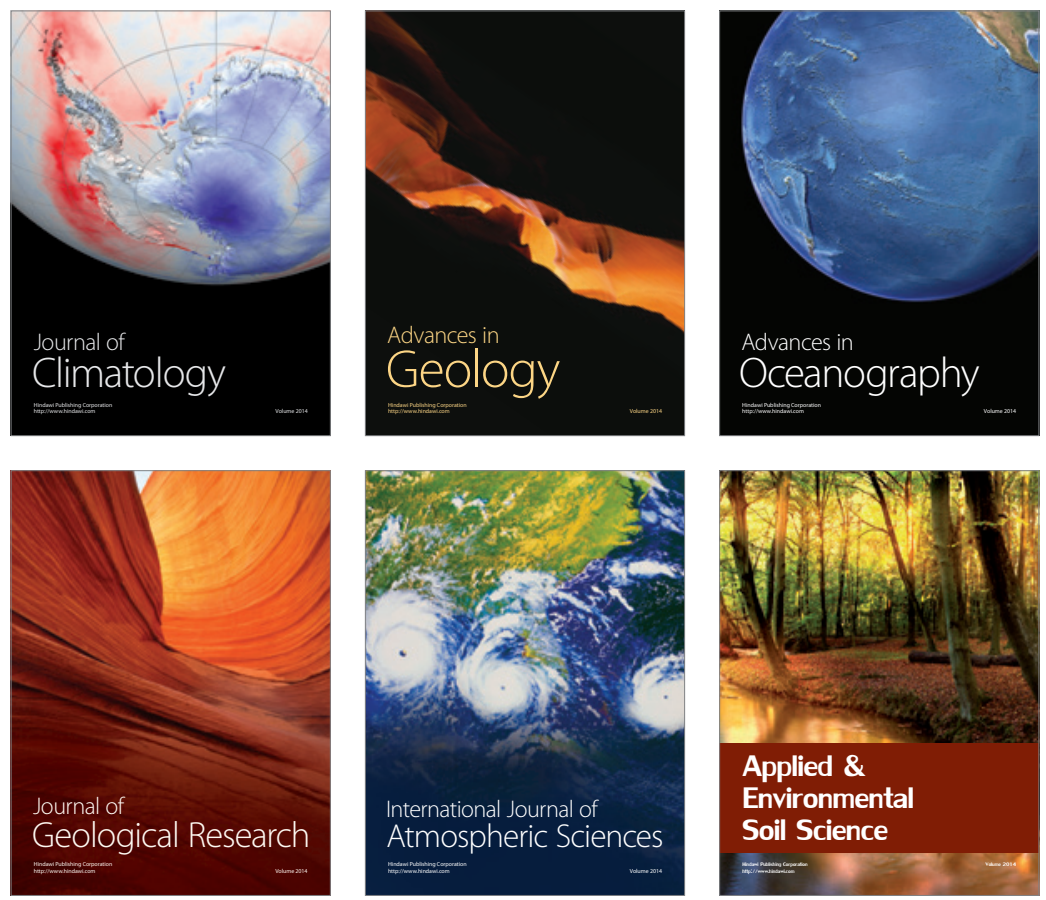
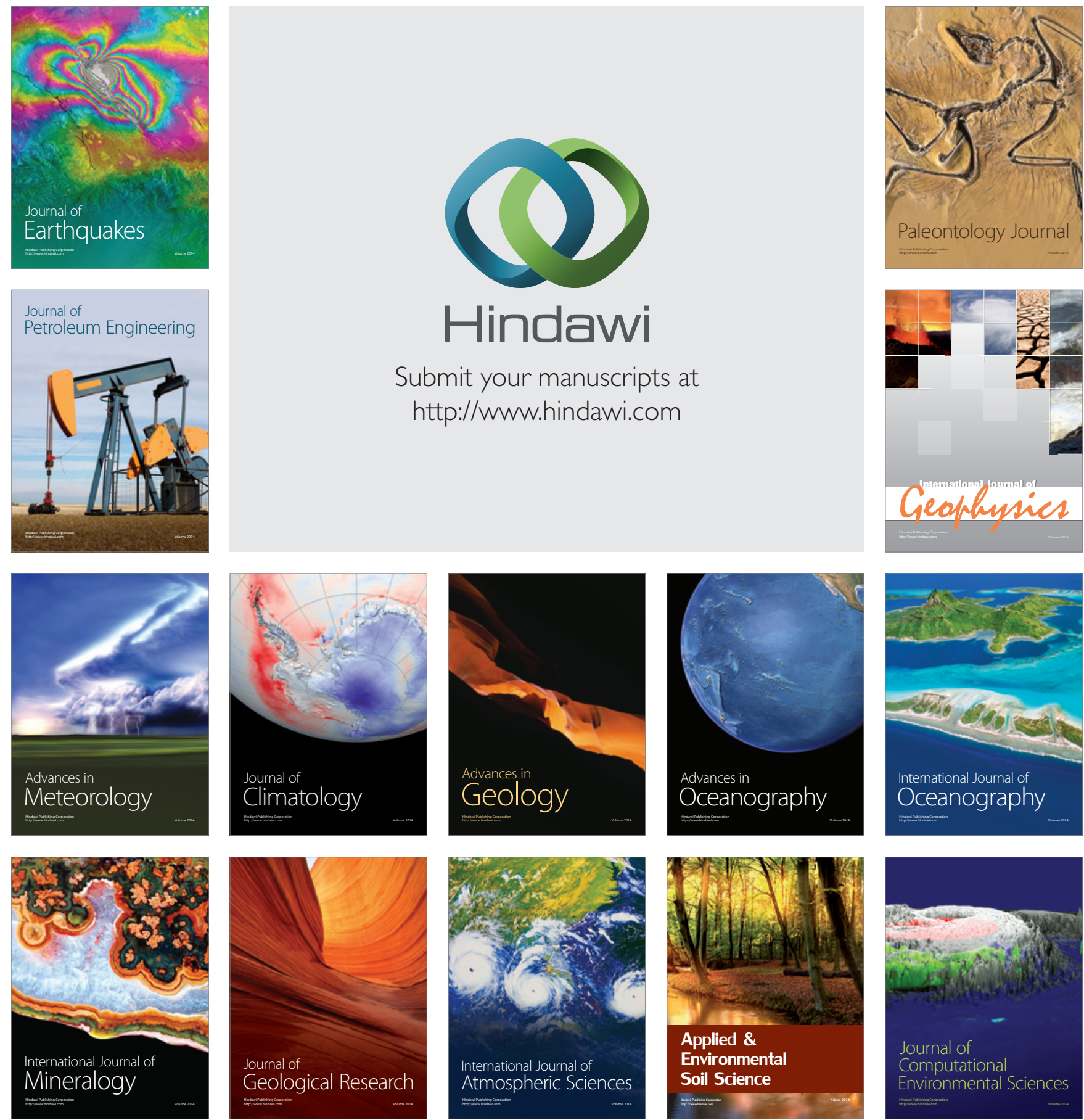